Review

\title{
Crosstalk between Depression and Dementia with Resting-State fMRI Studies and Its Relationship with Cognitive Functioning
}

\author{
Junhyung Kim ${ }^{1,2}$ and Yong-Ku Kim ${ }^{3, *(1)}$ \\ 1 Department of Psychiatry, Korea University Guro Hospital, Korea University College of Medicine, \\ Seoul 08308, Korea; jhcabilover@gmail.com \\ 2 Department of Psychiatry, Yonsei University College of Medicine, Seoul 03080, Korea \\ 3 Department of Psychiatry, Korea University Ansan Hospital, Korea University College of Medicine, \\ Ansan 15355, Korea \\ * Correspondence: yongku@korea.edu; Tel.: +82-10-9270-3259
}

Citation: Kim, J.; Kim, Y.-K.

Crosstalk between Depression and Dementia with Resting-State fMRI Studies and Its Relationship with Cognitive Functioning. Biomedicines 2021, 9, 82. https://doi.org/10.3390/ biomedicines 9010082

Received: 28 December 2020 Accepted: 13 January 2021 Published: 16 January 2021

Publisher's Note: MDPI stays neutral with regard to jurisdictional clai$\mathrm{ms}$ in published maps and institutional affiliations.

Copyright: (C) 2021 by the authors. Licensee MDPI, Basel, Switzerland. This article is an open access article distributed under the terms and conditions of the Creative Commons Attribution (CC BY) license (https:// creativecommons.org/licenses/by/ $4.0 /)$.

\begin{abstract}
Alzheimer's disease (AD) is the most common type of dementia, and depression is a risk factor for developing AD. Epidemiological studies provide a clinical correlation between late-life depression (LLD) and AD. Depression patients generally remit with no residual symptoms, but LLD patients demonstrate residual cognitive impairment. Due to the lack of effective treatments, understanding how risk factors affect the course of $\mathrm{AD}$ is essential to manage AD. Advances in neuroimaging, including resting-state functional MRI (fMRI), have been used to address neural systems that contribute to clinical symptoms and functional changes across various psychiatric disorders. Resting-state fMRI studies have contributed to understanding each of the two diseases, but the link between LLD and AD has not been fully elucidated. This review focuses on three crucial and well-established networks in AD and LLD and discusses the impacts on cognitive decline, clinical symptoms, and prognosis. Three networks are the (1) default mode network, (2) executive control network, and (3) salience network. The multiple properties emphasized here, relevant for the hypothesis of the linkage between LLD and AD, will be further developed by ongoing future studies.
\end{abstract}

Keywords: depression; late-life depression; dementia; Alzheimer's disease; neuroimaging; restingstate functional magnetic resonance imaging; default mode network; executive control network; salience network

\section{Introduction}

Dementia, one of the most common neurodegenerative disorders, is a devastating illness characterized by significant cognitive decline that induces interference in daily life and behavioral disturbances [1]. Alzheimer's disease (AD) is the most common dementia type, with worldwide patients expected to increase from 82 million in 2030 to 152 million in 2050 [2]. One in every 2-3 people over the age of 85 will develop AD-related dementia [3], and most $\mathrm{AD}$ patients experience mild cognitive impairment (MCI), which is the preclinical status of dementia with modest cognitive decline without dysfunction in daily life [4,5]. Several studies have established that the accumulation of amyloid $\beta$, hyperphosphorylation of tau proteins, and neuroinflammation affect the neurodegeneration seen in AD [6,7]. However, there is no effective drug for both delaying onset and restoring cognitive function. Therefore, delaying disease onset or progression could provide a significant reduction in the social and economic burden of these diseases [8]. For delaying or preventing AD, previous studies have found several modifiable risk factors, including diet, midlife hypertension, type 2 diabetes mellitus, smoking, cognitive/physical inactivity, traumatic brain injury, and depression [9-11].

Depression is the most prevalent coexisting noncognitive feature that occurs along with cognitive deficits and is associated with neurodegenerative disorders and cognitive decline [12-14]. Because a major depressive disorder (MDD) is a heterogeneous diagnostic 
category that features differences in symptom profiles, comorbidities, and the course of disease $[15,16]$, late-life depression (LLD) with an age of depression onset over 60 years has received a great deal of attention [17,18]. Moreover, the global number of individuals with LLD has increased by $27.1 \%$ from 2007 to 2017 [19]. Therefore, elucidating the link between the two disorders will help doctors and families understand and manage AD. Epidemiologic data have shown that LLD increases the risk of AD [20,21], and LLD is a risk factor that affects the progression of dementia from the normal cognition to $\mathrm{MCI}$ and from MCI to dementia [12,21-23]. Additionally, the risk of conversion from MCI to AD may vary due to the symptom severity of LLD or its successful treatment [24]. Individuals with LLD and high amyloid $\beta$ levels exhibited a shortened conversion time than those without depression and with high amyloid $\beta$ levels $[25,26]$. Altered levels and metabolism of amyloid $\beta$ seen in AD were also reported in individuals with LLD [27]. Although these findings support previously suggested mechanisms that connect depression and dementia [28], a previous systematic review pointed out that these results are not consistent with other studies [29]. This discrepancy may be due to the study population differences or methodologic differences between the various studies [30]. Therefore, it is necessary to subdivide the study population and conduct research associated with more specific criteria.

Cognitive impairments in individuals with depression have been consistently reported in meta-analyses and reviews [31-34]. Based on these results, difficulties with concentration and making decisions have been described as part of major depressive disorder (MDD) [1]. Cognitive impairments in MDD were reported across most domains [35,36]. These cognitive impairments in MDD patients are usually normalized after remission of the MDD $[35,36]$. However, studies using a comprehensive neuropsychological battery have reported that cognitive impairment in remitted LLD patients persisted in executive function and episodic memory compared to healthy controls [37-39]. In addition, a longitudinal study has reported that LLD patients exhibit a significant decline in all domains, and three-month remitters also exhibited a significant decline in verbal fluency and executive function [17], suggesting that certain aspects of executive functioning are associated with the traits of LLD. Although other studies reported inconsistent results with no difference in LLD [40-42], these inconsistent results may be attributed to the differences in cognitive tests. Episodic memory is the other main impaired cognitive domain in individuals with MCI [43]. Impairment in these cognitive domains was usually exhibited to a greater extent in individuals with LLD+MCI (and those with AD), relative to individuals with LLD [44-47].

In recent years, using improved neuroimaging technology, we can investigate brain structure and function through neuroimaging tools, magnetic resonance imaging (MRI), computed tomography, and positron emission tomography (PET). Among them, functional MRI (fMRI) can provide information about the properties of functional connectivity (FC) that is, collections of brain regions that are coactivated to support shared functions-during a task or rest (i.e., in the absence of stimuli) through measuring the blood oxygenation level-dependent (BOLD) signal [48,49]. More specifically, previous studies have suggested resting-state (rs)-fMRI as a promising method for investigating the behavioral characteristics including psychological states: sustained attention [50], personality [51], temperament traits [52], creative ability [53], and cognitive ability, such as working memory and motor performance [54]. These newer methods provide reproducible results and reflect stable trait-like neurobiological signatures $[55,56]$. Recent work also presents that the patterns of resting-state FC are uniquely related both to specific symptoms and to respond to different forms of treatment $[57,58]$. Thus, reviewing rs-fMRI results seems to be suitable for understanding the links between $\mathrm{AD} / \mathrm{MCI}$ and LLD.

\section{Methodological Overview of Resting-State fMRI (rs-fMRI) Studies}

Various analytical strategies are available to study resting-state network connectivity [59]. (1) Seed-based analysis is a hypothesis-driven approach when researchers initially select the seed region of interest based on their hypothesis and a calculated brain connec- 
tivity map by detecting temporal correlation [48]. Seed-based analyses are attractive for assessing FC changes in small samples with good statistical power; however, whole-brain analyses are required to address a more comprehensive understandings on changes in rs-fMRI [60]. (2) Regional homogeneity (ReHo) evaluates the similarity or synchronization between different time series given a region or given regions and their neighbors [61]. (3) Independent component analysis (ICA) is a more complex approach that decomposes the whole brain into a set of independent components as a functional map [62,63]. (4) Graph theory constructs models of interrelationships (represented by edges) between brain regions (represented by nodes) and assesses the state of the brain network using various measures [64,65]. (5) To address directional interaction within and between functional networks, incorporating resting-state effective connectivity have been conducted [66]. Data-driven techniques such as Granger causal analysis and Bayesian network analysis provide new insights into effective connectivity [66,67]. (6) The amplitude of low-frequency fluctuation (ALFF) and fractional ALFF (fALFF) techniques were developed to assess the spontaneous low frequency $(0.01-0.08 \mathrm{~Hz})$ fluctuations in the fMRI signal intensity at rest, which could reflect the intensity of regional brain spontaneous neural activity $[68,69]$.

Several rs-fMRI studies, aiming to unravel the neurobiological mechanisms of depression and dementia, have investigated abnormalities in various structures, including the frontal gyrus, precuneus, cingulate gyrus, parahippocampal cortex, cerebellum, or putamen [70-72]. However, recent meta-analyses of these studies did not reveal any significant regional convergence of neuroimaging findings for depression [73,74], suggesting that no single brain region is exclusively responsible for LLD's heterogeneous symptoms. A behavior or a clinical symptom typically involves synchronizing many brain regions in a network-based fashion [75]. Experiments have identified three major functional networks in LLD, AD, and MCI: (1) the default mode network (DMN), (2) executive control network (ECN), and (3) salience network (SN) [41,76-78]. Below, we review rs-fMRI studies in LLD, $\mathrm{AD}$, and MCI patients according to individual neural networks for ease of interpretation of the results associated with cognitive function. The analysis methods for resting-state functional connectivity, reference anatomy used for brain parcellation, types of scanners, and characteristics of groups included in the study are essential pieces of information to understand the study results clearly. Therefore, we presented the table which summarizes sample size, age, study type, scanner type, reference space, and analysis method of each section's key studies in Supplementary materials.

\section{The Default Mode Network (DMN)}

\subsection{Overview of $D M N$}

The DMN was initially described as brain regions that consistently showed synchronized deactivation during tasks and activation during rest [79]. This network now generally includes the medial prefrontal cortices (mPFCs), the posterior cingulate cortex (PCC), precuneus, inferior parietal lobule, lateral temporal cortex, and hippocampal formation [80,81]. The DMN is known to be normally deactivated during complex cognitive processing and active during rest, and further studies found that DMN activity is associated with internal processes, such as self-referential thinking [82], autobiographical memory [83], or thinking about the future [84]. Previous meta-analyses, including studies measuring ReHo, ALFF, and fALFF, suggested that altered DMN connectivity seems robust to the choice of analytical methods [85]. The DMN is generally divided into an anterior subdivision centered on the mPFC and a posterior subdivision centered on the PCC and the precuneus cortex $[80,86]$. Although both the anterior and posterior parts of the DMN are related to spontaneous or self-generated cognition, they seem to be different according to their specific functions [86,87]. Generally, the anterior DMN is more related to self-referential processing and emotion regulation, partly through its strong connections with limbic areas, and the posterior DMN has been implicated in both consciousness and memory processing through its relation to the hippocampal formation $[87,88]$. 


\section{2. rs-fMRI Studies Associated with DMN in Late-Life Depression (LLD)}

The fact that DMN is related to processes mostly employed during rest, such as self-generated thought, has gained significant attention, especially with studies related to depression [89]. DMN activity is considered to be negatively correlated to the ECN activity because reducing the brain's perspective processes seems necessary to focus on the imminent task [84]. In this line, failure to reduce DMN activity has been suggested as a sign of an inability to quiet or inhibit internal mentation or emotional processing [90]. Although not the focus of this review, the relative increases in DMN connectivity during tasks has been consistently reported in various task-based fMRI studies in individuals with depression [91,92]. Several rs-fMRI studies have also reported a relative increase in DMN connectivity [93].

In addition, the difference of connectivity pattern between the anterior and the posterior DMNs in individuals with LLD has been reported. Decreased FC in the posterior DMN have been reported in individuals with LLD compared to healthy controls by rs-fMRI studies using ReHo and ALFF [94-96]. Opposing elevation of FC in the anterior DMN was also observed in LLD patients [96]. This difference of FC between the anterior and the posterior DMNs, increased in the anterior DMN and decreased in the posterior DMN, has been also reported in rs-fMRI studies in younger adults with depressed moods compared to healthy controls $[77,97]$. Although the results in the elderly were not presented, several studies reported that the anterior and the posterior DMNs were associated with different depressive symptoms, rumination, and autobiographical memory, respectively [98]. Moreover, this difference persisted after 12 weeks of antidepressant treatment in young subjects who recovered from MDD [99].

Seed-based analysis that used seed regions of the PCC and precuneus reported interesting results. Unmedicated LLD patients presented with decreased PCC connectivity with increased connectivity in the anterior DMN at baseline. This decrease in connectivity was partly restored after 12 weeks of treatment with paroxetine [100], suggesting that connectivity between the anterior and posterior DMN regions reflects treatment effects. Seed-based analysis presented that the dissociation between the posterior DMN and ECN was also reported in LLD individuals with current depression compared to the healthy control group [92]. During the restoration of this dissociation after antidepressant treatment, it was also reported that the connectivity between PCC and MFG decreased at baseline, then the FC from PCC to the bilateral medial frontal gyrus increased after 12 weeks of antidepressant treatment in LLD patients [101]. In the seed-based analysis using $\mathrm{mPFC}$ as a seed region, the dissociation between the anterior and posterior DMNs in depression has been consistently reported in young adults [102,103]. Van Tol et al. (2014) reported increased connectivity between the mPFC and left anterior insula, indicating increased connectivity between the anterior DMN and the SN [103]. We presented key findings associated with LLD in Table 1 and characteristics of main rs-fMRI studies in Supplementary Table S1.

Table 1. Summary of key findings of resting-state functional MRI (rs-fMRI) studies associated with the default mode network (DMN) in late-life depression (LLD) patients included in the review.

\begin{tabular}{ccc}
\hline Summary of Key Findings & Key Studies \\
\hline Relative increase in DMN functional connectivity & [92] \\
Dissociation within DMN network & {$[94-96]$} \\
- decreased posterior DMN functional connectivity & - elevation anterior DMN functional connectivity & {$[100,101]$} \\
Restoration of dissociation within DMN network was associated with antidepressant treatment & \\
\hline
\end{tabular}

Abbreviations: DMN, Default mode network.

3.3. rs-fMRI Studies Associated with DMN in Alzheimer's Disease (AD) and Mild Cognitive Impairment $(\mathrm{MCI})$

The DMN has garnered considerable attention in rs-fMRI studies of neurodegenerative diseases, and the findings have been rather consistent. Early rs-fMRI studies focused on 
the hippocampus [104], because amyloidosis and tau pathology initially appear in the hippocampus [105-107], and hippocampal volume loss during the progression of AD is directly associated with cognitive decline in longitudinal studies $[108,109]$. Various seedbased analyses have reported that less hippocampal FC was found in a broad spectrum of cortical and subcortical regions in AD patients than in healthy individuals [110-112]. This altered hippocampal FC has been replicated in more recent seed-based analyses [113-117].

Various rs-fMRI studies that used ICA, fALFF, and ALFF to assess broader networks have also reported consistent results. While there are some inconsistent results in the exact regions reported as being affected by decreased connectivity, there are common significant regions that are nodes of the DMN in AD, including the precuneus and PCC [118-132]. Decreased connectivity within the DMN is often accompanied by increased connectivity in the frontoparietal network and SN [133]. In addition to these well-established results of the entire DMN, further studies addressed the dissociation between subdivisions of the DMN (anterior and posterior), suggested by ICA studies in AD patients [120]. There are both results with connectivity reductions mainly in the posterior DMN [134], but with altered connectivity to the anterior DMN $[135,136]$. In the dissociation between subdivisions of the DMN, an interesting result was reported in longitudinal studies. Findings from patients with early-onset Alzheimer's disease revealed an increase in the anterior DMN and decreased posterior DMN connectivity [120].

Analysis based on graph theory to assess the alteration of brain networks in $\mathrm{AD}$ has shown impressive results. The degree of centrality and clustering coefficients represent the density of a network that is reduced in AD patients [137-140], and networks in $\mathrm{AD}$ had longer distances than healthy controls with the loss of edges [141-143]. These studies also reported a negative correlation between small-worldness that reflected a balance between local processing and global integration in the human brain and disease severity [138-140]. Similar to overall network changes, small-worldness has been consistently reported in $\mathrm{AD}$ patients, asymptomatic apolipoprotein Apo $\varepsilon 4$ mutation carriers, and the aging elderly $[140,144]$. However, inconsistent results have reported an increase in the clustering coefficient in AD compared to healthy subjects [128,143].

Alteration of DMN connectivity is associated with a genetic mutation in AD. In particular, autosomal-dominant mutation carriers (PSEN1, PSEN2, or APP), who were young and asymptomatic, presented with altered DMN connectivity [145-147]. Regarding the Apo $\varepsilon 4$ allele, various studies have reported diminished DMN connectivity in carriers of at least one Apo $\varepsilon 4$ allele in all age ranges [144,146-151]. These results suggest some potential for the use of DMN connectivity for early identification of AD in young adults who carry relevant genetic mutations. Moreover, rs-fMRI studies have also reported DMN connectivity changes before the amyloidosis detected by Pittsburgh compound B [152-154], which can support the potential of DMN connectivity as an early marker of AD.

The clinical implication of DMN connectivity has been investigated in various areas. Altered DMN connectivity was correlated with the extent of cognitive decline in middle-aged and elderly Apo $\varepsilon 4$ allele carriers [155-157]. This association has been shown consistently in $\mathrm{AD}$ or $\mathrm{MCI}$ patients related to global cognition and episodic memory performance [127,158-161]. With consistent results of altered DMN connectivity in rs-fMRI studies, attention has been focused on how these alterations can be counteracted by treatment [78]. Studies on donepezil's effect on the resting-state networks in AD have found that the application of donepezil leads to an increase in previously reduced connectivity with no differences in study groups at baseline $[162,163]$.

Additionally, altered connectivity between the anterior and posterior DMNs is associated with aging and age-related cognitive decline $[147,164]$. This dissociation in DMN subdivision has also been shown in the cognitively normal elderly who presented with abnormal cerebrospinal fluid amyloid or tau proteins [165], or cerebral amyloidosis detected by PET [166]. These results are congruent with the idea that AD patients have a long preclinical period with functional alterations before the onset of disease symptoms. For the network connectivity changes in the progression of $\mathrm{AD}$, longitudinal studies reported 
decreased connectivity between the precuneus and ECN [167], different local aging patterns in the FC between the left hippocampus and the PCC [168], and decreased global connectivity associated with the striatum [169]. Based on the suggested potential of DMN to provide biomarkers, several rs-fMRI studies have addressed early detection, classification, and prediction in $\mathrm{AD}$ and $\mathrm{MCI}$. These studies have shown relatively high performances: ICA [161,170-173], seed-based analysis [174], and graph theory [175]. We presented key findings associated with $\mathrm{AD}$ and MCI in Table 2 and characteristics of main rs-fMRI studies in Supplementary Tables S2 and S3.

Table 2. Summary of key findings of rs-fMRI studies associated with the default mode network (DMN) in Alzheimer's disease (AD) and mild cognitive impairment (MCI) patients included in the review.

\begin{tabular}{cc}
\hline Summary of Key Findings & Key Studies \\
\hline Decreased in DMN functional connectivity & Dissociation within DMN network; \\
- decreased posterior DMN functional connectivity & {$[112,118,123,126-128,131]$} \\
- elevation anterior DMN functional connectivity & {$[134,135]$} \\
DMN networks had longer distances with the loss of edges & {$[138,141,142]$} \\
Altered DMN functional connectivity was associated with decline of cognition & {$[143,158,160]$} \\
Altered DMN functional connectivity was associated with genetic mutation & {$[146,149,152,154,157,163]$} \\
\hline Abbreviations: DMN, default mode network.
\end{tabular}

\section{The Executive Control Network (ECN)}

\subsection{Overview of ECN}

The ECN, a functionally linked system, consists of brain structure cores that include the dorsolateral prefrontal cortex (dlPFC), medial frontal cortex, lateral parietal cortex, cerebellum, and supplementary motor area [176]. Initially, studies investigating executive function using task-based fMRI identified the coactivation patterns of an ECN during executive function tasks [177]. Beyond task-based fMRI, rs-fMRI studies, and structural MRI studies have also identified an ECN [176,178]. Moreover, a close correlation between executive function changes with aging and alterations in the ECN have been reported [179]. This correlation has been reported in studies that used the ECN to study the functional mechanisms of executive function changes in patients with psychiatric disorders, Parkinson's disease [180], MCI [181], AD [182], and LLD [183].

\section{2. rs-fMRI Studies Associated with ECN in LLD}

Disruption of the ECN in LLD patients with current depression symptoms has been consistently reported compared to healthy controls [184,185]. Particularly, seed-based analyses using the dIPFC as the seed region demonstrated decreased FC in the frontoparietal areas in LLD individuals with current depression [41]. Other studies using the cerebellum as a seed region reported decreased FC in ECN nodes, including in dIPFC and the parietal cortex, as well as DMN nodes $[186,187]$. Studies using ICA analysis presented different connectivity patterns for each region in the ECN, with increased FC in the inferior parietal but decreased FC in the dIPFC and superior frontal areas [39]. This decreased connectivity associated with the ECN has been consistently presented in other rs-fMRI studies using ReHo [94,188] and ALFF [40]. Additionally, LLD remitters also demonstrated decreased FC in the frontal-parietal cortex 3 months after remission [189]. After 21 months, individuals with remitted LLD presented a return to decreased FC.

Executive dysfunction is a common symptom in LLD patients. About 30 to $40 \%$ of nondemented elders with LLD demonstrate executive dysfunction during neuropsychological tests [190]. Disruption of the ECN was associated with executive dysfunction that included susceptibility to distraction, an inability to sustain attention, poor multitasking, organizational difficulties, and concrete or rigid thinking [191]. A recent study reported that LLD patients' FC between the dIPFC and other bilateral regions was negatively associated with executive function in LLD subjects [192]. Researchers reported that executive 
dysfunction is associated with greater functional disability levels in LLD [193,194]. Deficits in word-list generation and response inhibition that represent executive function predict poor and slow antidepressant responses and relapses $[195,196]$. In this regard, the ECN seems to be related to the LLD's clinical prognosis associated with executive dysfunction. We presented key findings associated with LLD in Table 3 and characteristics of main rs-fMRI studies in Supplementary Table S4.

Table 3. Summary of key findings of rs-fMRI studies associated with the executive control network (ECN) in late-life depression (LLD) patients included in the review.

\begin{tabular}{cc}
\hline Summary of Key Findings & Key Studies \\
\hline Decreased in ECN functional connectivity & {$[186,188]$} \\
Restoration of ECN functional connectivity after remission & {$[189]$} \\
Decreased in ECN functional connectivity was associated with executive dysfunction & {$[192]$}
\end{tabular}

Abbreviations: ECN, executive control network.

\section{3. rs-fMRI studies associated with the ECN in $A D$ and $M C I$}

Additionally, in $\mathrm{AD}$ and MCI, rs-fMRI studies using the ICA analysis identified a significant difference in ECN connectivity across AD and MCI patients and normal controls [197]. In the case of intraconnectivity of the ECN, results seem inconclusive, with some studies reporting no changes in $\mathrm{AD}$ patients and others reporting increased connectivity [121,127,198]. However, studies using seed-based analysis consistently reported abnormal FCs between the hippocampus and nodes of the ECN. Previous studies have demonstrated that functional brain activity within portions of the ECN was abnormal in patients with $\mathrm{MCI}$ and AD [182,199]. Specifically, the directed FCs from the left hippocampus to the right superior frontal gyrus (SFG) and left medial frontal gyrus (MFG) to the right hippocampus were significantly decreased in MCI or AD patients. The SFG [175] and the MFG $[200,201]$ are essential components of the dIPFC that play essential roles in the ECN.

Moreover, Cai et al. (2017) reported different effective connectivity patterns for the $\mathrm{ECN}$ in normal controls and three subgroups of MCI: (1) MCI-R-MCI reverted to the normal functioning state and stabilized to the normal state in 24 months; (2) MCI-SMCI patients who remained in a stable disease state for 24 months; (3) MCI-P-MCI that progressed to $\mathrm{AD}$ and stabilized to $\mathrm{AD}$ in 24 months. In this study, the effective connectivity patterns in the ECN were less disrupted and less obvious among MCI-R and MCI-S to MCI-P. In addition, ECN connectivity strengths were not changed in MCI-R patients and normal controls compared to MCI-S and MCI-P patients [181]. These results suggest the importance of the ECN in dementia progression from MCI to AD. We presented key findings associated with $\mathrm{AD}$ and $\mathrm{MCI}$ in Table 4 and characteristics of main rs-fMRI studies in Supplementary Table S5.

Table 4. Summary of key findings of rs-fMRI studies associated with the executive control network (ECN) in Alzheimer's disease $(\mathrm{AD})$ and mild cognitive impairment (MCI) patients included in the review.

\begin{tabular}{ccc}
\hline Summary of Key Findings & Key Studies \\
\hline Decreased in ECN functional connectivity & {$[197]$} \\
Inconclusive result was also reported (increased ECN functional connectivity in AD) & {$[198]$} & {$[181]$} \\
ECN functional connectivity was associated with AD progression & \\
\hline
\end{tabular}

Abbreviations: ECN, executive control network; AD, Alzheimer's disease.

\section{The Salience Network (SN)}

\subsection{Overview of $S N$}

The SN is the brain network that detects and filters external stimuli and recruits relevant functional networks [202]. This network is essential for detecting and integrating emotional and sensory stimuli, allocating attention, and switching between internally directed cognition and externally directed cognition [203]. The SN's hub is the ventral 
anterior insula [204], and the SN also includes nodes in the amygdala, hypothalamus, ventral striatum, and thalamus [203]. The SN was suggested to be functionally subdivided into dorsal and ventral components that support cognitive and emotional controls, respectively [205]. The key SN regions activated during cognitive tasks consist of dorsal components: the dorsal anterior cingulate cortex and the right anterior insula $[205,206]$. For example, the $\mathrm{SN}$ engages the ECN and disengages the DMN during cognitive tasks but does the opposite during rest [207]. Regarding cognitive function, the extent of dissociation between the ECN and SN is related to cognitive task performance [208]. Additionally, the structural connectivity shown by diffusion tensor image analysis is also positively correlated with SN intraconnectivity (right anterior insula to dorsal anterior cingulate cortex) and deactivation of the DMN during tasks, which is in turn related to cognitive function [209].

\section{2. rs-fMRI Studies Associated with the SN in LLD}

A disrupted standard pattern of SN connectivity is suggested to be one of the key traits of the pathogenesis of depression, particularly in the insula and amygdala [210]. Elevated connectivity between the insula and DMN was enhanced in MDD patients, which may hinder the above standard pattern [91]. The FC from the amygdala, another important $\mathrm{SN}$ node, to the hippocampus was decreased in adolescents with depression and at a high risk of depression [211,212]. Additionally, seed-based analysis in younger adults using the amygdala as a seed region was positively associated with increased amygdala FC with DMN nodes and long-term negative emotions [213]. One study that addressed apathy in LLD patients found that LLD patients with apathy exhibit increased FC between the SN and DMN compared with nonapathetic elders with depression [77]. Overall, these results may suggest that increased FC between the $\mathrm{SN}$ and DMN may predispose individuals to depression and is further correlated with vegetative symptoms in LLD [186]. However, inconsistent results for decreased FC between the amygdala and precuneus in depressed patients compared with controls have been reported [214].

Network analysis reported that elders with LLD also demonstrate a decreased negative FC between the SN and ECN compared to nondepressed age-matched controls [39]. Another study that compared correlation patterns among significant brain networks in LLD patients compared to nondepressed elderly controls reported dissociation patterns among the ECN/SN, and DMN observed in controls [215]. These results represent a failure of internetwork cohesiveness in LLD [185]. Moreover, decreased negative FC between the $\mathrm{ECN}$ and the $\mathrm{SN}$ was associated with cognitive impairment and severity of depression symptoms in LLD patients [39]. In addition, a worse treatment response to antidepressants was also associated with this disrupted standard SN pattern [216]. We presented key findings associated with LLD in Table 5 and characteristics of main rs-fMRI studies in Supplementary Table S6.

Table 5. Summary of key findings of rs-fMRI studies associated with the salience network (SN) in late-life depression (LLD) patients included in the review.

\begin{tabular}{ccc}
\hline Summary of Key Findings & Key Studies & {$[39]$} \\
Decreased SN functional connectivity & {$[77,215]$} & {$[216]$} \\
Increased functional connectivity between SN and DMN & Disrupted SN pattern was associated with worse treatment response & \\
\hline
\end{tabular}

Abbreviations: DMN, default mode network; SN, salience network.

\section{3. rs-fMRI Studies Associated with $S N$ in $A D$ and $M C I$}

SN connectivity has increasingly gained attention from researchers who address neurodegenerative disease [133]. Although intensified SN connectivity was observed in AD patients compared to healthy controls in ICA studies [130,170], another ICA study in AD patients found contradictory evidence of a decrease in dorsal SN [121]. This increased SN connectivity has been consistently reported in cognitively normal individuals with elevated 
amyloid levels [166,217], Apo $\varepsilon 4$ carriers [156,218], and MCI patients [74]. Moreover, studies that have addressed both amyloid and tau within the DMN and SN reported interesting results, with increased connectivity in the SN and DMN in individuals with elevated amyloid but little evidence of tau, but decreased connectivity in the SN and DMN in individuals with both elevated tau and amyloid levels [219]. These findings highlight the point that $\mathrm{SN}$ connectivity changes occur in preclinical dementia, and $\mathrm{SN}$ connectivity may change with disease progression. We presented key findings associated with $\mathrm{AD}$ and MCI in Table 6 and characteristics of main rs-fMRI studies in Supplementary Table S7.

Table 6. Summary of key findings of main rs-fMRI studies associated with the salience network (SN) in Alzheimer's disease (AD) and mild cognitive impairment (MCI) patients included in the review.

\begin{tabular}{cc}
\hline Summary of Key Findings & Key Studies \\
\hline Intensified SN functional connectivity was observed in AD patients & {$[170]$} \\
Increased SN functional connectivity was associated with & - elevation of amyloid level, Apo $\varepsilon 4$ carriers, and elevation of tau \\
\hline
\end{tabular}

Abbreviations: $\mathrm{SN}$, salience network; AD, Alzheimer's disease.

\section{Conclusions}

Alteration in brain networks during the resting state contributes to the symptoms and progression of LLD and AD. Above, we described LLD and AD, focusing on key networks known to be necessary for the network-level description of these two diseases: the DMN, ECN, and SN (Figure 1). A growing body of literature suggests an opposite direction for overall DMN alterations in LLD and AD, with increased connectivity of the DMN in LLD but decreased DMN connectivity in AD. However, the dissociation between the anterior DMN and posterior DMN provides insight into the link between depression and dementia. In the early stage of AD, the alteration in the DMN is different between its anterior and posterior subdivisions, with increased anterior DMN connectivity, and decreased posterior DMN connectivity [120]. Similar dissociation patterns were also observed in individuals with depression, and this increased anterior DMN persists after antidepressant treatments [99]. Additionally, a posterior DMN connectivity reduction was observed in individuals with LLD + MCI compared to LLD only $[46,188]$ and also in LLD patients with an inadequate response to treatment [101]. Additionally, the PCC, the hub of the posterior $\mathrm{DMN}$, is a marker of very early AD progression, as consistently seen with T1-weighted imaging, postmortems, and PET studies [220-222]. Although this association between the dissociation of DMN connectivity and AD and LLD remains to be explored, severe depression may induce the clinical manifestation of cognitive impairment or the onset of eventual cognitive decline, a signal of intrinsic network dysfunction.

Regarding the ECN, both AD and LLD exhibit disrupted ECN connectivity. As discussed, executive dysfunction associated with disrupted ECN connectivity seems to be related to the clinical prognosis of LLD with poor and slow antidepressant responses and a high relapse rate. The findings that the degree of ECN disruption is associated with cognitive decline 24 months after MCI is also covered above. With the hypothesis that depression precedes cognitive decline or induces cognitive decline [223], these results suggest the possibility that the ECN is a target that can modify the impact of LLD on cognitive declines. A noninvasive treatment is being conducted with the ECN as a target [224].

Another interesting issue seen in rs-fMRI studies is associated with the pathogenic process. Several studies using rs-fMRI associated with AD, tau, and amyloid pathology consistently reported that the spreading of these pathologies throughout the brain correlates to brain network disruption, as discussed in this review. Because the DMN, ECN, and $\mathrm{SN}$ are multimodal networks that are metabolically expensive and display high rates of cerebral blood flow, aerobic glycolysis, and oxidative glucose metabolism [225], these networks may be vulnerable to AD-associated pathogenic processes. Although spatial deposition patterns have been not convergent, there has been a recent observation that tau and amyloid plaques overlap with brain tissue loss in hub regions of these discussed 
brain networks [226]. Another review also points to this correlation and suggests that AD-associated pathophysiological processes may explain changes in these networks [133].

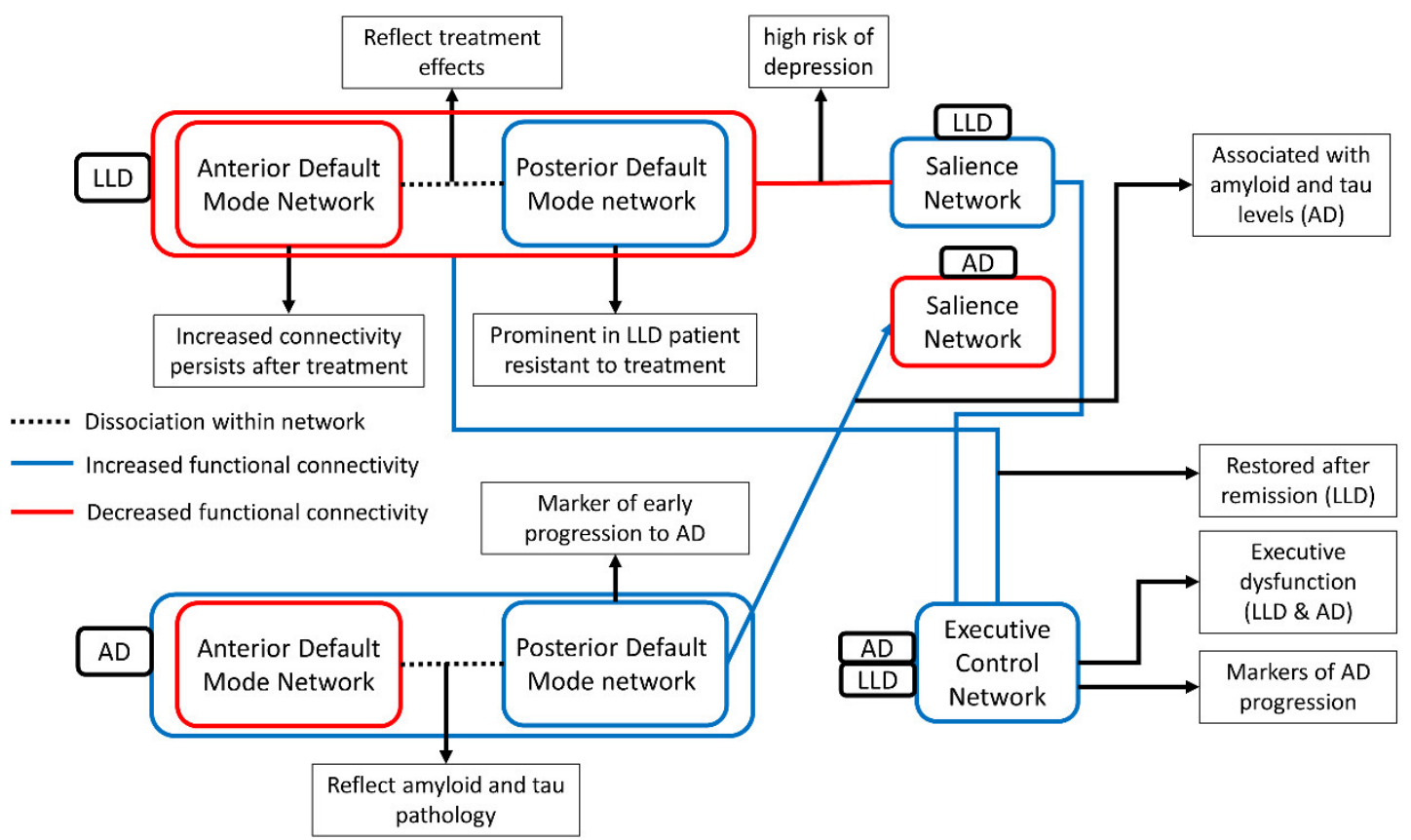

Figure 1. The figure presents the aberrant functional connectivity between three networks in AD and LLD and its clinical implication. Blue line and red line indicate the decreased functional connectivity and the increased functional connectivity compared with healthy control, respectively. Decreased functional connectivity of the executive control network was commonly observed in AD and LLD [192,197]. In contrast, the functional connectivity of the salience network and the default mode network were differently altered. The default mode network connectivity decreased in AD and increased in LLD $[93,127]$, and the salience network increased in AD and decreased in LLD [130,215]. However, dissociated functional connectivity pattern in DMN, increased in the anterior DMN and decreased in the posterior DMN, was commonly observed in both AD and LLD [96,166]. This dissociation reflects treatment effects in LLD and amyloid/tau pathology in AD [100,165]. This similarity of dissociation seems to be a possible mechanism of association between LLD and AD highlighted in epidemiological studies.

Despite the consistent findings across studies, several critical knowledge gaps remain. The lack of standardized protocol for addressing the brain using rs-fMRI has not been adequately addressed. Regarding preprocessing steps of fMRI for dealing with noise, preprocessing steps for rs-fMRI data have evolved to be more diverse than preprocessing for task-based fMRI data. With the diversity of statistical approaches applied to the purified data, these nonstandardized various methods make comparisons across studies extremely difficult. Even if the same terms are used to describe results such as network strength or connectivity, one method's results cannot be compared well with the results of studies using other technologies.

Additionally, our literature did not include task-based fMRI studies in AD and LDD, which clearly expressed the need for additional research. Compared to rs-fMRI studies, a task-based fMRI study is a relatively conventional approach and is challenging to perform due to the needs of involving tasks. Nevertheless, preprocessing steps and statistical methods for task-based fMRI have been more standardized than those for rs-fMRI and have less influenced results, where an external behavioral standard is available. Because taskbased fMRI studies are more clinically interpretable, future studies that include tailored tasks concerning specific cognitive, emotional, and social functions would expand our knowledge of AD and LLD.

Recent studies using directed graph theory or combining multiple imaging tools have presented promising results in the field of diagnosis and prediction $[227,228]$. Therefore, 
future studies combining multimodal imaging tools such as PET, MRI, and fMRI in AD and LLD patients samples with special considerations such as age, sex, age of onset, treatment outcomes, the severity of illness, and cognitive impairment would help us understand the fundamental functional pathological changes in AD and LLD. Longitudinal studies that include various treatment tools would also help uncover the association between depression and AD-associated pathophysiological processes. Standardized protocols in fMRI data collection and analysis would be helpful to reduce heterogeneity across these physiological states.

Supplementary Materials: The following are available online at https:/ / www.mdpi.com/2227-905 9/9/1/82/s1.

Author Contributions: J.K. reviewed and summarized articles, prepared figures, and wrote the manuscript. Y.-K.K. conceived the structure of the paper, supervised the review, organized the figures, and wrote the manuscript. All authors contributed to the critical reading and writing of the manuscript. All authors have read and agreed to the published version of the manuscript.

Funding: This research received no external funding.

Institutional Review Board Statement: Not applicable.

Informed Consent Statement: Not applicable.

Data Availability Statement: No new data were created or analyzed in this study. Data sharing is not applicable to this article.

Conflicts of Interest: The author declares no conflict of interest.

\section{References}

1. Association, A.P. Diagnostic and Statistical Manual of Mental Disorders (DSM- $\left.5^{\circledR}\right)$; American Psychiatric Pub: Washington, DC, USA, 2013; ISBN 0890425574.

2. World Health Organization. Dementia. Available online: https://www.who.int/news-room/fact-sheets/detail/dementia (accessed on 21 December 2020).

3. Hebert, L.E.; Weuve, J.; Scherr, P.A.; Evans, D.A. Alzheimer disease in the United States (2010-2050) estimated using the 2010 census. Neurology 2013, 80, 1778-1783. [CrossRef] [PubMed]

4. Petersen, R.C.; Stevens, J.C.; Ganguli, M.; Tangalos, E.G.; Cummings, J.L.; DeKosky, S.T. Practice parameter: Early detection of dementia: Mild cognitive impairment. Neurology 2001, 56, 1133-1142. [CrossRef] [PubMed]

5. Association, A. 2018 Alzheimer's disease facts and figures. Alzheimer's Dement. 2018, 14, 367-429. [CrossRef]

6. Greenberg, S.M.; Bacskai, B.J.; Hernandez-Guillamon, M.; Pruzin, J.; Sperling, R.; van Veluw, S.J. Cerebral amyloid angiopathy and Alzheimer disease-One peptide, two pathways. Nat. Rev. Neurol. 2020, 16, 30-42. [CrossRef]

7. Ozben, T.; Ozben, S. Neuro-inflammation and anti-inflammatory treatment options for Alzheimer's disease. Clin. Biochem. 2019, 72, 87-89. [CrossRef]

8. Brookmeyer, R.; Johnson, E.; Ziegler-Grahamm, K.; Arrighi, H.M. Forecasting the global prevalence and burden of Alzheimer's disease. Alzheimer's Dement. 2007, 3, 186-191. [CrossRef]

9. Baumgart, M.; Snyder, H.M.; Carrillo, M.C.; Fazio, S.; Kim, H.; Johns, H. Summary of the evidence on modifiable risk factors for cognitive decline and dementia: A population-based perspective. Alzheimer's Dement. 2015, 11, 718-726. [CrossRef]

10. Xu, W.; Tan, L.; Wang, H.-F.; Jiang, T.; Tan, M.-S.; Tan, L.; Zhao, Q.-F.; Li, J.-Q.; Wang, J.; Yu, J.-T. Meta-analysis of modifiable risk factors for Alzheimer's disease. J. Neurol. 2015, 86, 1299-1306. [CrossRef]

11. Clare, L.; Wu, Y.-T.; Teale, J.C.; MacLeod, C.; Matthews, F.; Brayne, C.; Woods, B.; Team, C.-W. study Potentially modifiable lifestyle factors, cognitive reserve, and cognitive function in later life: A cross-sectional study. PLoS Med. 2017, 14, e1002259. [CrossRef]

12. Chi, S.; Wang, C.; Jiang, T.; Zhu, X.-C.; Yu, J.-T.; Tan, L. The Prevalence of Depression in Alzheimer's Disease: A Systematic Review and Meta-Analysis. Curr. Alzheimer Res. 2015, 12, 189-198. [CrossRef]

13. Fuchs, E. Neurogenesis in the adult brain: Is there an association with mental disorders? Eur. Arch. Psychiatry Clin. Neurosci. 2007, 257, 247-249. [CrossRef] [PubMed]

14. Herbert, J.; Lucassen, P.J. Depression as a risk factor for Alzheimer's disease: Genes, steroids, cytokines and neurogenesis-What do we need to know? Front. Neuroendocrinol. 2016, 41, 153-171. [CrossRef] [PubMed]

15. Goldberg, D. The heterogeneity of "major depression". World Psychiatry 2011, 10, 226-228. [CrossRef] [PubMed]

16. Lynch, C.J.; Gunning, F.M.; Liston, C. Causes and Consequences of Diagnostic Heterogeneity in Depression: Paths to Discovering Novel Biological Depression Subtypes. Biol. Psychiatry 2020, 88, 83-94. [CrossRef] 
17. Riddle, M.; Potter, G.G.; McQuoid, D.R.; Steffens, D.C.; Beyer, J.L.; Taylor, W.D. Longitudinal Cognitive Outcomes of Clinical Phenotypes of Late-Life Depression. Am. J. Geriatr. Psychiatry 2017, 25, 1123-1134. [CrossRef]

18. Leggett, A.; Zarit, S.H.; Hoang, C.N.; Nguyen, H.T. Correlates of cognitive impairment in older Vietnamese. Aging Ment. Health 2013, 17, 915-923. [CrossRef]

19. Tedros, A.G.; Christopher, J.L.M. Global Burden of Disease Study 2017. Lancet 2017, 5, 1-27.

20. Ownby, R.L.; Crocco, E.; Acevedo, A.; John, V.; Loewenstein, D. Depression and Risk for Alzheimer Disease: Systematic Review, Meta-analysis, and Metaregression Analysis. Arch. Gen. Psychiatry 2006, 63, 530-538. [CrossRef]

21. Diniz, B.S.; Sibille, E.; Ding, Y.; Tseng, G.; Aizenstein, H.J.; Lotrich, F.; Becker, J.T.; Lopez, O.L.; Lotze, M.T.; Klunk, W.E.; et al. Plasma biosignature and brain pathology related to persistent cognitive impairment in late-life depression. Mol. Psychiatry 2015, 20, 594-601. [CrossRef]

22. Brailean, A.; Aartsen, M.J.; Muniz-Terrera, G.; Prince, M.; Prina, A.M.; Comijs, H.C.; Huisman, M.; Beekman, A. Longitudinal associations between late-life depression dimensions and cognitive functioning: A cross-domain latent growth curve analysis. Psychol. Med. 2017, 47, 690-702. [CrossRef]

23. Ismail, Z.; Elbayoumi, H.; Fischer, C.E.; Hogan, D.B.; Millikin, C.P.; Schweizer, T.; Mortby, M.E.; Smith, E.E.; Patten, S.B.; Fiest, K.M. Prevalence of Depression in Patients with Mild Cognitive Impairment: A Systematic Review and Meta-analysis. JAMA Psychiatry 2017, 74, 58-67. [CrossRef] [PubMed]

24. Almeida, O.P.; Hankey, G.J.; Yeap, B.B.; Golledge, J.; Flicker, L. Depression as a modifiable factor to decrease the risk of dementia. Transl. Psychiatry 2017, 7, e1117. [CrossRef] [PubMed]

25. Brendel, M.; Pogarell, O.; Xiong, G.; Delker, A.; Bartenstein, P.; Rominger, A. Depressive symptoms accelerate cognitive decline in amyloid-positive MCI patients. Eur. J. Nucl. Med. Mol. Imaging 2015, 42, 716-724. [CrossRef] [PubMed]

26. Mahgoub, N.; Alexopoulos, G.S. Amyloid Hypothesis: Is There a Role for Antiamyloid Treatment in Late-Life Depression? Am. J. Geriatr. Psychiatry 2016, 24, 239-247. [CrossRef] [PubMed]

27. Do Nascimento, K.K.F.; Silva, K.P.; Malloy-Diniz, L.F.; Butters, M.A.; Diniz, B.S. Plasma and cerebrospinal fluid amyloid- $\beta$ levels in late-life depression: A systematic review and meta-analysis. J. Psychiatr. Res. 2015, 69, 35-41. [CrossRef] [PubMed]

28. Butters, M.A.; Young, J.B.; Lopez, O.; Aizenstein, H.J.; Mulsant, B.H.; Reynolds, C.F., 3rd; DeKosky, S.T.; Becker, J.T. Pathways linking late-life depression to persistent cognitive impairment and dementia. Dialogues Clin. Neurosci. 2008, 10, 345-357.

29. Geerlings, M.I.; Gerritsen, L. Late-Life Depression, Hippocampal Volumes, and Hypothalamic-Pituitary-Adrenal Axis Regulation: A Systematic Review and Meta-analysis. Biol. Psychiatry 2017, 82, 339-350. [CrossRef] [PubMed]

30. Edwards Iii, G.A.; Gamez, N.; Escobedo, G., Jr.; Calderon, O.; Moreno-Gonzalez, I. Modifiable Risk Factors for Alzheimer's Disease. Front. Aging Neurosci. 2019, 11, 146-163. [CrossRef]

31. Epp, A.M.; Dobson, K.S.; Dozois, D.J.A.; Frewen, P.A. A systematic meta-analysis of the Stroop task in depression. Clin. Psychol. Rev. 2012, 32, 316-328. [CrossRef]

32. Monteiro, S.; Monteiro, B.; Candida, M.; Adler, N.; Campos, C.; Rocha, N.B.F.; Paes, F.; Nardi, A.E.; Machado, S. Association between depression severity and executive functioning in late-life depression: A systematic review. Med. Express 2016, 3, 1-9. [CrossRef]

33. Roca, M.; Vives, M.; López-Navarro, E.; García-Campayo, J.; Gili, M. Cognitive impairments and depression: A critical review. Actas Esp. Psiquiatr. 2015, 43, 187-193. [PubMed]

34. Weisenbach, S.L.; Kumar, A. Current Understanding of the Neurobiology and Longitudinal Course of Geriatric Depression. Curr. Psychiatry Rep. 2014, 16, 463-471. [CrossRef] [PubMed]

35. Rock, P.L.; Roiser, J.P.; Riedel, W.J.; Blackwell, A.D. Cognitive impairment in depression: A systematic review and meta-analysis. Psychol. Med. 2014, 44, 2029-2040. [CrossRef]

36. Ahern, E.; Semkovska, M. Cognitive functioning in the first-episode of major depressive disorder: A systematic review and meta-analysis. Neuropsychology 2017, 31, 52-72. [CrossRef] [PubMed]

37. Liao, W.; Zhang, X.; Shu, H.; Wang, Z.; Liu, D.; Zhang, Z. The characteristic of cognitive dysfunction in remitted late life depression and amnestic mild cognitive impairment. Psychiatry Res. 2017, 251, 168-175. [CrossRef]

38. Chen, J.; Shu, H.; Wang, Z.; Zhan, Y.; Liu, D.; Liao, W.; Xu, L.; Liu, Y.; Zhang, Z. Convergent and divergent intranetwork and internetwork connectivity patterns in patients with remitted late-life depression and amnestic mild cognitive impairment. Cortex 2016, 83, 194-211. [CrossRef]

39. Li, W.; Wang, Y.; Ward, B.D.; Antuono, P.G.; Li, S.-J.; Goveas, J.S. Intrinsic inter-network brain dysfunction correlates with symptom dimensions in late-life depression. J. Psychiatr. Res. 2017, 87, 71-80. [CrossRef]

40. Yue, Y.; Jia, X.; Hou, Z.; Zang, Y.; Yuan, Y. Frequency-dependent amplitude alterations of resting-state spontaneous fluctuations in late-onset depression. Biomed. Res. Int. 2015, 2015, 1-9. [CrossRef]

41. Alexopoulos, G.S.; Hoptman, M.J.; Kanellopoulos, D.; Murphy, C.F.; Lim, K.O.; Gunning, F.M. Functional connectivity in the cognitive control network and the default mode network in late-life depression. J. Affect. Disord. 2012, 139, 56-65. [CrossRef]

42. Li, X.; Steffens, D.C.; Potter, G.G.; Guo, H.; Song, S.; Wang, L. Decreased between-hemisphere connectivity strength and network efficiency in geriatric depression. Hum. Brain Mapp. 2017, 38, 53-67. [CrossRef]

43. Ozer, S.; Young, J.; Champ, C.; Burke, M. A systematic review of the diagnostic test accuracy of brief cognitive tests to detect amnestic mild cognitive impairment. Int. J. Geriatr. Psychiatry 2016, 31, 1139-1150. [CrossRef] [PubMed] 
44. Bai, F.; Shu, N.; Yuan, Y.; Shi, Y.; Yu, H.; Wu, D.; Wang, J.; Xia, M.; He, Y.; Zhang, Z. Topologically Convergent and Divergent Structural Connectivity Patterns between Patients with Remitted Geriatric Depression and Amnestic Mild Cognitive Impairment. J. Neurosci. 2012, 32, 4307-4318. [CrossRef] [PubMed]

45. Wang, Z.; Jia, X.; Liang, P.; Qi, Z.; Yang, Y.; Zhou, W.; Li, K. Changes in thalamus connectivity in mild cognitive impairment: Evidence from resting state fMRI. Eur. J. Radiol. 2012, 81, 277-285. [CrossRef] [PubMed]

46. Li, H.-J.; Hou, X.-H.; Liu, H.-H.; Yue, C.-L.; He, Y.; Zuo, X.-N. Toward systems neuroscience in mild cognitive impairment and Alzheimer's disease: A meta-analysis of 75 fMRI studies. Hum. Brain Mapp. 2015, 36, 1217-1232. [CrossRef] [PubMed]

47. Shimoda, K.; Kimura, M.; Yokota, M.; Okubo, Y. Comparison of regional gray matter volume abnormalities in Alzheimer's disease and late life depression with hippocampal atrophy using VSRAD analysis: A voxel-based morphometry study. Psychiatry Res. Neuroimaging 2015, 232, 71-75. [CrossRef]

48. Biswal, B.; Zerrin Yetkin, F.; Haughton, V.M.; Hyde, J.S. Functional connectivity in the motor cortex of resting human brain using echo-planar MRI. Magn. Reson. Med. 1995, 34, 537-541. [CrossRef]

49. Smitha, K.A.; Akhil Raja, K.; Arun, K.M.; Rajesh, P.G.; Thomas, B.; Kapilamoorthy, T.R.; Kesavadas, C. Resting state fMRI A review on methods in resting state connectivity analysis and resting state networks. Neuroradiol. J. 2017, 30, 305-317. [CrossRef]

50. Rosenberg, M.D.; Finn, E.S.; Scheinost, D.; Papademetris, X.; Shen, X.; Constable, R.T.; Chun, M.M. A neuromarker of sustained attention from whole-brain functional connectivity. Nat. Neurosci. 2016, 19, 165-171. [CrossRef]

51. Hsu, W.-T.; Rosenberg, M.D.; Scheinost, D.; Constable, R.T.; Chun, M.M. Resting-state functional connectivity predicts neuroticism and extraversion in novel individuals. Soc. Cogn. Affect. Neurosci. 2018, 13, 224-232. [CrossRef]

52. Jiang, R.; Calhoun, V.D.; Zuo, N.; Lin, D.; Li, J.; Fan, L.; Qi, S.; Sun, H.; Fu, Z.; Song, M.; et al. Connectome-based individualized prediction of temperament trait scores. Neuroimage 2018, 183, 366-374. [CrossRef]

53. Beaty, R.E.; Kenett, Y.N.; Christensen, A.P.; Rosenberg, M.D.; Benedek, M.; Chen, Q.; Fink, A.; Qiu, J.; Kwapil, T.R.; Kane, M.J.; et al. Robust prediction of individual creative ability from brain functional connectivity. Proc. Natl. Acad. Sci. USA 2018, 115, 1087-1092. [CrossRef] [PubMed]

54. Siegel, J.S.; Ramsey, L.E.; Snyder, A.Z.; Metcalf, N.V.; Chacko, R.V.; Weinberger, K.; Baldassarre, A.; Hacker, C.D.; Shulman, G.L.; Corbetta, M. Disruptions of network connectivity predict impairment in multiple behavioral domains after stroke. Proc. Natl. Acad. Sci. USA 2016, 113, E4367-E4376. [CrossRef] [PubMed]

55. Jalbrzikowski, M.; Liu, F.; Foran, W.; Calabro, F.J.; Roeder, K.; Devlin, B.; Luna, B. Cognitive and default mode networks support developmental stability in functional connectome fingerprinting through adolescence. bioRxiv 2019, 812719. [CrossRef]

56. Gratton, C.; Laumann, T.O.; Nielsen, A.N.; Greene, D.J.; Gordon, E.M.; Gilmore, A.W.; Nelson, S.M.; Coalson, R.S.; Snyder, A.Z.; Schlaggar, B.L.; et al. Functional Brain Networks Are Dominated by Stable Group and Individual Factors, Not Cognitive or Daily Variation. Neuron 2018, 98, 439-452.e5. [CrossRef] [PubMed]

57. Kühn, S.; Vanderhasselt, M.-A.; De Raedt, R.; Gallinat, J. Why ruminators won't stop: The structural and resting state correlates of rumination and its relation to depression. J. Affect. Disord. 2012, 141, 352-360. [CrossRef]

58. Brakowski, J.; Spinelli, S.; Dörig, N.; Bosch, O.G.; Manoliu, A.; Holtforth, M.G.; Seifritz, E. Resting state brain network function in major depression-Depression symptomatology, antidepressant treatment effects, future research. J. Psychiatr. Res. 2017, 92, 147-159. [CrossRef]

59. Takamura, T.; Hanakawa, T. Clinical utility of resting-state functional connectivity magnetic resonance imaging for mood and cognitive disorders. J. Neural Transm. 2017, 124, 821-839. [CrossRef]

60. Lee, M.H.; Smyser, C.D.; Shimony, J.S. Resting-state fMRI: A review of methods and clinical applications. Am. J. Neuroradiol. 2013, 34, 1866-1872. [CrossRef]

61. Zang, Y.; Jiang, T.; Lu, Y.; He, Y.; Tian, L. Regional homogeneity approach to fMRI data analysis. Neuroimage 2004, 22, 394-400. [CrossRef]

62. Mckeown, M.J.; Sejnowski, T.J. Independent Component Analysis of fMRI Data: Examining the Assumptions. Hum. Brain Mapp. 1998, 6, 368-372. [CrossRef]

63. Van De Ven, V.G.; Formisano, E.; Prvulovic, D.; Roeder, C.H.; Linden, D.E.J. Functional Connectivity as Revealed by Spatial Independent Component Analysis of fMRI Measurements During Rest. Hum. Brain Mapp. 2004, 22, 165-178. [CrossRef] [PubMed]

64. Bullmore, E.; Sporns, O. Complex brain networks: Graph theoretical analysis of structural and functional systems. Nat. Rev. Neurosci. 2009, 10, 186-198. [CrossRef] [PubMed]

65. Bassett, D.S.; Bullmore, E.T. Small-World Brain Networks Revisited. Neuroscientist 2016, 23, 499-516. [CrossRef]

66. Friston, K.J. Functional and effective connectivity in neuroimaging: A synthesis. Hum. Brain Mapp. 1994, 2, 56-78. [CrossRef]

67. Liang, P.; Li, Z.; Deshpande, G.; Wang, Z.; Hu, X.; Li, K. Altered causal connectivity of resting state brain networks in amnesic MCI. PLoS ONE 2014, 9, e88476. [CrossRef]

68. Yu-Feng, Z.; Yong, H.; Chao-Zhe, Z.; Qing-Jiu, C.; Man-Qiu, S.; Meng, L.; Li-Xia, T.; Tian-Zi, J.; Yu-Feng, W. Altered baseline brain activity in children with ADHD revealed by resting-state functional MRI. Brain Dev. 2007, 29, 83-91. [CrossRef]

69. Zou, Q.-H.; Zhu, C.-Z.; Yang, Y.; Zuo, X.-N.; Long, X.-Y.; Cao, Q.-J.; Wang, Y.-F.; Zang, Y.-F. An improved approach to detection of amplitude of low-frequency fluctuation (ALFF) for resting-state fMRI: Fractional ALFF. J. Neurosci. Methods 2008, 172, 137-141. [CrossRef]

70. Geng, J.; Yan, R.; Shi, J.; Chen, Y.; Mo, Z.; Shao, J.; Wang, X.; Yao, Z.; Lu, Q. Altered regional homogeneity in patients with somatic depression: A resting-state fMRI study. J. Affect. Disord. 2019, 246, 498-505. [CrossRef] 
71. Peng, D.; Liddle, E.B.; Iwabuchi, S.J.; Zhang, C.; Wu, Z.; Liu, J.; Jiang, K.; Xu, L.; Liddle, P.F.; Palaniyappan, L.; et al. Dissociated large-scale functional connectivity networks of the precuneus in medication-naïve first-episode depression. Psychiatry Res. Neuroimaging 2015, 232, 250-256. [CrossRef]

72. Liu, F.; Hu, M.; Wang, S.; Guo, W.; Zhao, J.; Li, J.; Xun, G.; Long, Z.; Zhang, J.; Wang, Y.; et al. Abnormal regional spontaneous neural activity in first-episode, treatment-naive patients with late-life depression: A resting-state fMRI study. Prog. Neuro-Psychopharmacol. Biol. Psychiatry 2012, 39, 326-331. [CrossRef]

73. Gray, J.P.; Müller, V.I.; Eickhoff, S.B.; Fox, P.T. Multimodal Abnormalities of Brain Structure and Function in Major Depressive Disorder: A Meta-Analysis of Neuroimaging Studies. Am. J. Psychiatry 2020, 177, 422-434. [CrossRef] [PubMed]

74. Müller, V.I.; Cieslik, E.C.; Serbanescu, I.; Laird, A.R.; Fox, P.T.; Eickhoff, S.B. Altered Brain Activity in Unipolar Depression Revisited: Meta-analyses of Neuroimaging Studies. JAMA Psychiatry 2017, 74, 47-55. [CrossRef] [PubMed]

75. Marek, S.; Tervo-Clemmens, B.; Nielsen, A.N.; Wheelock, M.D.; Miller, R.L.; Laumann, T.O.; Earl, E.; Foran, W.W.; Cordova, M.; Doyle, O.; et al. Identifying reproducible individual differences in childhood functional brain networks: An ABCD study. Dev. Cogn. Neurosci. 2019, 40, 100706. [CrossRef] [PubMed]

76. Mulders, P.C.; van Eijndhoven, P.F.; Schene, A.H.; Beckmann, C.F.; Tendolkar, I. Resting-state functional connectivity in major depressive disorder: A review. Neurosci. Biobehav. Rev. 2015, 56, 330-344. [CrossRef]

77. Yuen, G.S.; Gunning-Dixon, F.M.; Hoptman, M.J.; AbdelMalak, B.; McGovern, A.R.; Seirup, J.K.; Alexopoulos, G.S. The salience network in the apathy of late-life depression. Int. J. Geriatr. Psychiatry 2014, 29, 1116-1124. [CrossRef]

78. Hohenfeld, C.; Werner, C.J.; Reetz, K. Resting-state connectivity in neurodegenerative disorders: Is there potential for an imaging biomarker? NeuroImage Clin. 2018, 18, 849-870. [CrossRef]

79. Greicius, M.D.; Ben, K.; Allan, L.R.; Vinod, M. Functional connectivity in the resting brain: A network analysis of the default mod hypothesis. Proc. Natl. Acad. Sci. USA 2003, 100, 253-258. [CrossRef]

80. Buckner, R.L.; Andrews-Hanna, J.R.; Schacter, D.L. The Brain's Default Network. Ann. N. Y. Acad. Sci. 2008, 1124, 1-38. [CrossRef]

81. Mohan, A.; Roberto, A.J.; Mohan, A.; Lorenzo, A.; Jones, K.; Carney, M.J.; Liogier-Weyback, L.; Hwang, S.; Lapidus, K.A.B. The Significance of the Default Mode Network (DMN) in Neurological and Neuropsychiatric Disorders: A Review. Yale J. Biol. Med. 2016, 89, 49-57.

82. Kyeong, S.; Kim, J.; Kim, J.; Kim, E.J.; Kim, H.E.; Kim, J.-J. Differences in the modulation of functional connectivity by self-talk tasks between people with low and high life satisfaction. Neuroimage 2020, 217, 116929. [CrossRef]

83. Spreng, R.N.; Mar, R.A.; Kim, A.S.N. The common neural basis of autobiographical memory, prospection, navigation, theory of mind, and the default mode: A quantitative meta-analysis. J. Cogn. Neurosci. 2009, 21, 489-510. [CrossRef] [PubMed]

84. Raichle, M.E. The Brain's Default Mode Network. Annu. Rev. Neurosci. 2015, 38, 433-447. [CrossRef] [PubMed]

85. Buckner, R.L.; Sepulcre, J.; Talukdar, T.; Krienen, F.M.; Liu, H.; Hedden, T.; Andrews-Hanna, J.R.; Sperling, R.A.; Johnson, K.A. Cortical Hubs Revealed by Intrinsic Functional Connectivity: Mapping, Assessment of Stability, and Relation to Alzheimer's Disease. J. Neurosci. 2009, 29, 1860-1873. [CrossRef] [PubMed]

86. Andrews-Hanna, J.R.; Reidler, J.S.; Sepulcre, J.; Poulin, R.; Buckner, R.L. Functional-Anatomic Fractionation of the Brain's Default Network. Neuron 2010, 65, 550-562. [CrossRef] [PubMed]

87. Andrews-Hanna, J.R.; Smallwood, J.; Spreng, R.N. The default network and self-generated thought: Component processes, dynamic control, and clinical relevance. Ann. N. Y. Acad. Sci. 2014, 1316, 29-52. [CrossRef] [PubMed]

88. Leech, R.; Sharp, D.J. The role of the posterior cingulate cortex in cognition and disease. Brain 2014, 137, 12-32. [CrossRef]

89. Menon, V. Large-scale brain networks and psychopathology: A unifying triple network model. Trends Cogn. Sci. 2011, 15, 483-506. [CrossRef]

90. Scalabrini, A.; Vai, B.; Poletti, S.; Damiani, S.; Mucci, C.; Colombo, C.; Zanardi, R.; Benedetti, F.; Northoff, G. All roads lead to the default-mode network-global source of DMN abnormalities in major depressive disorder. Neuropsychopharmacology 2020, 45, 2058-2069. [CrossRef]

91. Connolly, C.G.; Wu, J.; Ho, T.C.; Hoeft, F.; Wolkowitz, O.; Eisendrath, S.; Frank, G.; Hendren, R.; Max, J.E.; Paulus, M.P.; et al. Resting-State Functional Connectivity of Subgenual Anterior Cingulate Cortex in Depressed Adolescents. Biol. Psychiatry 2013, 74, 898-907. [CrossRef]

92. Yin, Y.; He, X.; Xu, M.; Hou, Z.; Song, X.; Sui, Y.; Liu, Z.; Jiang, W.; Yue, Y.; Zhang, Y.; et al. Structural and functional connectivity of default mode network underlying the cognitive impairment in late-onset depression. Sci. Rep. 2016, 6, 1-10. [CrossRef]

93. Posner, J.; Hellerstein, D.J.; Gat, I.; Mechling, A.; Klahr, K.; Wang, Z.; McGrath, P.J.; Stewart, J.W.; Peterson, B.S. Antidepressants Normalize the Default Mode Network in Patients with Dysthymia. JAMA Psychiatry 2013, 70, 373-382. [CrossRef] [PubMed]

94. Yuan, Y.; Zhang, Z.; Bai, F.; Yu, H.; Shi, Y.; Qian, Y.; Liu, W.; You, J.; Zhang, X.; Liu, Z. Abnormal neural activity in the patients with remitted geriatric depression: A resting-state functional magnetic resonance imaging study. J. Affect. Disord. 2008, 111, 145-152. [CrossRef] [PubMed]

95. Chen, J.; Liu, F.; Xun, G.; Chen, H.; Hu, M.; Guo, X.; Xiao, C.; Wooderson, S.C.; Guo, W.; Zhao, J. Early and late onset, first-episode, treatment-naive depression: Same clinical symptoms, different regional neural activities. J. Affect. Disord. $2012,143,56-63$. [CrossRef] [PubMed]

96. Steffens, D.C.; Wang, L.; Manning, K.J.; Pearlson, G.D. Negative Affectivity, Aging, and Depression: Results from the Neurobiology of Late-Life Depression (NBOLD) Study. Am. J. Geriatr. Psychiatry 2017, 25, 1135-1149. [CrossRef] 
97. Guo, W.; Liu, F.; Zhang, J.; Zhang, Z.; Yu, L.; Liu, J.; Chen, H.; Xiao, C. Abnormal default-mode network homogeneity in first-episode, drug-naive major depressive disorder. PLoS ONE 2014, 9, e91102. [CrossRef]

98. Zhu, X.; Wang, X.; Xiao, J.; Liao, J.; Zhong, M.; Wang, W.; Yao, S. Evidence of a Dissociation Pattern in Resting-State Default Mode Network Connectivity in First-Episode, Treatment-Naive Major Depression Patients. Biol. Psychiatry 2012, 71, 611-617. [CrossRef]

99. Li, B.; Liu, L.; Friston, K.J.; Shen, H.; Wang, L.; Zeng, L.-L.; Hu, D. A Treatment-Resistant Default Mode Subnetwork in Major Depression. Biol. Psychiatry 2013, 74, 48-54. [CrossRef]

100. Wu, M.; Andreescu, C.; Butters, M.A.; Tamburo, R.; Reynolds, C.F.; Aizenstein, H. Default-mode network connectivity and white matter burden in late-life depression. Psychiatry Res. Neuroimaging 2011, 194, 39-46. [CrossRef]

101. Andreescu, C.; Tudorascu, D.L.; Butters, M.A.; Tamburo, E.; Patel, M.; Price, J.; Karp, J.F.; Reynolds, C.F.; Aizenstein, H. Resting state functional connectivity and treatment response in late-life depression. Psychiatry Res. Neuroimaging 2013, 214, 313-321. [CrossRef]

102. Sheline, Y.I.; Price, J.L.; Yan, Z.; Mintun, M.A. Resting-state functional MRI in depression unmasks increased connectivity between networks via the dorsal nexus. Proc. Natl. Acad. Sci. USA 2010, 107, 11020-11025. [CrossRef]

103. Van Tol, M.J.; Li, M.; Metzger, C.D.; Hailla, N.; Horn, D.I.; Li, W.; Heinze, H.J.; Bogerts, B.; Steiner, J.; He, H.; et al. Local cortical thinning links to resting-state disconnectivity in major depressive disorder. Psychol. Med. 2014, 44, 2053-2065. [CrossRef] [PubMed]

104. Braak, H.; Braak, E.; Bohl, J. Staging of Alzheimer-Related Cortical Destruction. Eur. Neurol. 1993, 33, 403-408. [CrossRef] [PubMed]

105. Braak, H.; Braak, E. Neuropathological stageing of Alzheimer-related changes. Acta Neuropathol. 1991, 82, 239-259. [CrossRef] [PubMed]

106. Hanseeuw, B.J.; Schultz, A.P.; Betensky, R.A.; Sperling, R.A.; Johnson, K.A. Decreased hippocampal metabolism in high-amyloid mild cognitive impairment. Alzheimer's Dement. 2016, 12, 1288-1296. [CrossRef] [PubMed]

107. Serra, L.; Bozzali, M.; Fadda, L.; De Simone, M.S.; Bruschini, M.; Perri, R.; Caltagirone, C.; Carlesimo, G.A. The role of hippocampus in the retrieval of autobiographical memories in patients with amnestic Mild Cognitive Impairment due to Alzheimer's disease. J. Neuropsychol. 2018, 14, 46-68. [CrossRef] [PubMed]

108. Den Heijer, T.; van der Lijn, F.; Koudstaal, P.J.; Hofman, A.; van der Lugt, A.; Krestin, G.P.; Niessen, W.J.; Breteler, M.M.B. A 10-year follow-up of hippocampal volume on magnetic resonance imaging in early dementia and cognitive decline. Brain 2010, 133, 1163-1172. [CrossRef]

109. Steffens, D.C.; McQuoid, D.R.; Payne, M.E.; Potter, G.G. Change in Hippocampal Volume on Magnetic Resonance Imaging and Cognitive Decline Among Older Depressed and Nondepressed Subjects in the Neurocognitive Outcomes of Depression in the Elderly Study. Am. J. Geriatr. Psychiatry 2011, 19, 4-12. [CrossRef]

110. Allen, G.; Barnard, H.; McColl, R.; Hester, A.L.; Fields, J.A.; Weiner, M.F.; Ringe, W.K.; Lipton, A.M.; Brooker, M.; McDonald, E.; et al. Reduced Hippocampal Functional Connectivity in Alzheimer Disease. Arch. Neurol. 2007, 64, 1482-1487. [CrossRef]

111. Li, S.-J.; Li, Z.; Wu, G.; Zhang, M.-J.; Franczak, M.; Antuono, P.G. Alzheimer Disease: Evaluation of a Functional MR Imaging Index as a Marker. Radiology 2002, 225, 253-259. [CrossRef]

112. Wang, L.; Zang, Y.; He, Y.; Liang, M.; Zhang, X.; Tian, L.; Wu, T.; Jiang, T.; Li, K. Changes in hippocampal connectivity in the early stages of Alzheimer's disease: Evidence from resting state fMRI. Neuroimage 2006, 31, 496-504. [CrossRef]

113. Das, S.R.; Pluta, J.; Mancuso, L.; Kliot, D.; Yushkevich, P.A.; Wolk, D.A. Anterior and posterior MTL networks in aging and MCI. Neurobiol. Aging 2015, 36, S141-S150. [CrossRef] [PubMed]

114. Kenny, E.R.; Blamire, A.M.; Firbank, M.J.; O’Brien, J.T. Functional connectivity in cortical regions in dementia with Lewy bodies and Alzheimer's disease. Brain 2012, 135, 569-581. [CrossRef] [PubMed]

115. Sohn, W.S.; Yoo, K.; Na, D.L.; Jeong, Y. Progressive Changes in Hippocampal Resting-state Connectivity Across Cognitive Impairment: A Cross-sectional Study from Normal to Alzheimer Disease. Alzheimer Dis. Assoc. Disord. 2014, 28, 239-246. [CrossRef] [PubMed]

116. Tahmasian, M.; Pasquini, L.; Scherr, M.; Meng, C.; Förster, S.; Mulej Bratec, S.; Shi, K.; Yakushev, I.; Schwaiger, M.; Grimmer, T.; et al. The lower hippocampus global connectivity, the higher its local metabolism in Alzheimer disease. Neurology 2015, 84, 1956-1963. [CrossRef]

117. Sun, Y.; Wang, Y.; Lu, J.; Liu, R.; Schwarz, C.G.; Zhao, H.; Zhang, Y.; Xu, L.; Zhu, B.; Zhang, B.; et al. Disrupted functional connectivity between perirhinal and parahippocampal cortices with hippocampal subfields in patients with mild cognitive impairment and Alzheimer's disease. Oncotarget 2017, 8, 99112-99124. [CrossRef]

118. Agosta, F.; Pievani, M.; Geroldi, C.; Copetti, M.; Frisoni, G.B.; Filippi, M. Resting state fMRI in Alzheimer's disease: Beyond the default mode network. Neurobiol. Aging 2012, 33, 1564-1578. [CrossRef]

119. Hafkemeijer, A.; Möller, C.; Dopper, E.G.P.; Jiskoot, L.C.; Schouten, T.M.; van Swieten, J.C.; van der Flier, W.M.; Vrenken, H.; Pijnenburg, Y.A.L.; Barkhof, F.; et al. Resting state functional connectivity differences between behavioral variant frontotemporal dementia and Alzheimer's disease. Front. Hum. Neurosci. 2015, 9, 1-12. [CrossRef]

120. Damoiseaux, J.S.; Prater, K.E.; Miller, B.L.; Greicius, M.D. Functional connectivity tracks clinical deterioration in Alzheimer's disease. Neurobiol. Aging 2012, 33, 828.e19-828.e30. [CrossRef]

121. Filippi, M.; Agosta, F.; Scola, E.; Canu, E.; Magnani, G.; Marcone, A.; Valsasina, P.; Caso, F.; Copetti, M.; Comi, G.; et al. Functional network connectivity in the behavioral variant of frontotemporal dementia. Cortex 2013, 49, 2389-2401. [CrossRef] 
122. Franciotti, R.; Falasca, N.W.; Bonanni, L.; Anzellotti, F.; Maruotti, V.; Comani, S.; Thomas, A.; Tartaro, A.; Taylor, J.-P.; Onofrj, M. Default network is not hypoactive in dementia with fluctuating cognition: An Alzheimer disease/dementia with Lewy bodies comparison. Neurobiol. Aging 2013, 34, 1148-1158. [CrossRef]

123. Gili, T.; Cercignani, M.; Serra, L.; Perri, R.; Giove, F.; Maraviglia, B.; Caltagirone, C.; Bozzali, M. Regional brain atrophy and functional disconnection across Alzheimer's disease evolution. J. Neurol. Neurosurg. Psychiatry 2011, 82, 58-66. [CrossRef] [PubMed]

124. Griffanti, L.; Dipasquale, O.; Laganà, M.M.; Nemni, R.; Clerici, M.; Smith, S.M.; Baselli, G.; Baglio, F. Effective artifact removal in resting state fMRI data improves detection of DMN functional connectivity alteration in Alzheimer's disease. Front. Hum. Neurosci. 2015, 9, 1-11. [CrossRef] [PubMed]

125. Schwindt, G.C.; Chaudhary, S.; Crane, D.; Ganda, A.; Masellis, M.; Grady, C.L.; Stefanovic, B.; Black, S.E. Modulation of the Default-Mode Network Between Rest and Task in Alzheimer's Disease. Cereb. Cortex 2013, 23, 1685-1694. [CrossRef] [PubMed]

126. Wang, Z.; Yan, C.; Zhao, C.; Qi, Z.; Zhou, W.; Lu, J.; He, Y.; Li, K. Spatial patterns of intrinsic brain activity in mild cognitive impairment and alzheimer's disease: A resting-state functional MRI study. Hum. Brain Mapp. 2011, 32, 1720-1740. [CrossRef] [PubMed]

127. Weiler, M.; Fukuda, A.; Massabki, L.; Lopes, T.; Franco, A.; Damasceno, B.; Cendes, F.; Balthazar, M. Default Mode, Executive Function, and Language Functional Connectivity Networks are Compromised in Mild Alzheimer's Disease. Curr. Alzheimer Res. 2014, 11, 274-282. [CrossRef]

128. Zhang, Z.; Liu, Y.; Jiang, T.; Zhou, B.; An, N.; Dai, H.; Wang, P.; Niu, Y.; Wang, L.; Zhang, X. Altered spontaneous activity in Alzheimer's disease and mild cognitive impairment revealed by Regional Homogeneity. Neuroimage 2012, 59, 1429-1440. [CrossRef]

129. Zhou, W.; Xia, Z.; Bi, Y.; Shu, H. Altered connectivity of the dorsal and ventral visual regions in dyslexic children: A resting-state fMRI study. Front. Hum. Neurosci. 2015, 9, 495-504. [CrossRef]

130. Balthazar, M.L.F.; Pereira, F.R.S.; Lopes, T.M.; da Silva, E.L.; Coan, A.C.; Campos, B.M.; Duncan, N.W.; Stella, F.; Northoff, G.; Damasceno, B.P.; et al. Neuropsychiatric symptoms in Alzheimer's disease are related to functional connectivity alterations in the salience network. Hum. Brain Mapp. 2014, 35, 1237-1246. [CrossRef]

131. Binnewijzend, M.A.A.; Schoonheim, M.M.; Sanz-Arigita, E.; Wink, A.M.; van der Flier, W.M.; Tolboom, N.; Adriaanse, S.M.; Damoiseaux, J.S.; Scheltens, P.; van Berckel, B.N.M.; et al. Resting-state fMRI changes in Alzheimer's disease and mild cognitive impairment. Neurobiol. Aging 2012, 33, 2018-2028. [CrossRef]

132. Brier, M.R.; Thomas, J.B.; Snyder, A.Z.; Benzinger, T.L.; Zhang, D.; Raichle, M.E.; Holtzman, D.M.; Morris, J.C.; Ances, B.M. Loss of Intranetwork and Internetwork Resting State Functional Connections with Alzheimer's Disease Progression. J. Neurosci. 2012, 32, 8890-8899. [CrossRef]

133. Badhwar, A.; Tam, A.; Dansereau, C.; Orban, P.; Hoffstaedter, F.; Bellec, P. Resting-state network dysfunction in Alzheimer's disease: A systematic review and meta-analysis. Alzheimer's Dement. Diagn. Assess. Dis. Monit. 2017, 8, 73-85. [CrossRef] [PubMed]

134. Koch, K.; Myers, N.E.; Göttler, J.; Pasquini, L.; Grimmer, T.; Förster, S.; Manoliu, A.; Neitzel, J.; Kurz, A.; Förstl, H.; et al. Disrupted Intrinsic Networks Link Amyloid- $\beta$ Pathology and Impaired Cognition in Prodromal Alzheimer's Disease. Cereb. Cortex 2015, 25, 4678-4688. [CrossRef] [PubMed]

135. Jones, D.T.; Vemuri, P.; Murphy, M.C.; Gunter, J.L.; Senjem, M.L.; Machulda, M.M.; Przybelski, S.A.; Gregg, B.E.; Kantarci, K.; Knopman, D.S.; et al. Non-Stationarity in the “Resting Brain's" Modular Architecture. PLoS ONE 2012, 7, e39731. [CrossRef] [PubMed]

136. Song, J.; Qin, W.; Liu, Y.; Duan, Y.; Liu, J.; He, X.; Li, K.; Zhang, X.; Jiang, T.; Yu, C. Aberrant Functional Organization within and between Resting-State Networks in AD. PLoS ONE 2013, 8, e63727. [CrossRef] [PubMed]

137. Guo, Z.; Liu, X.; Hou, H.; Wei, F.; Liu, J.; Chen, X. Abnormal degree centrality in Alzheimer's disease patients with depression: A resting-state functional magnetic resonance imaging study. Exp. Gerontol. 2016, 79, 61-66. [CrossRef] [PubMed]

138. Brier, M.R.; Thomas, J.B.; Fagan, A.M.; Hassenstab, J.; Holtzman, D.M.; Benzinger, T.L.; Morris, J.C.; Ances, B.M. Functional connectivity and graph theory in preclinical Alzheimer's disease. Neurobiol. Aging 2014, 35, 757-768. [CrossRef] [PubMed]

139. Sun, Y.; Yin, Q.; Fang, R.; Yan, X.; Wang, Y.; Bezerianos, A. Disrupted Functional Brain Connectivity and Its Association to Structural Connectivity in Amnestic Mild Cognitive Impairment and Alzheimer's Disease. PLoS ONE 2014, 9, e96505. [CrossRef]

140. Toussaint, P.-J.; Maiz, S.; Coynel, D.; Doyon, J.; Messé, A.; de Souza, L.C.; Sarazin, M.; Perlbarg, V.; Habert, M.-O.; Benali, H. Characteristics of the default mode functional connectivity in normal ageing and Alzheimer's disease using resting state fMRI with a combined approach of entropy-based and graph theoretical measurements. Neuroimage 2014, 101, 778-786. [CrossRef]

141. Sanz-arigita, E.J.; Schoonheim, M.M.; Damoiseaux, J.S.; Rombouts, S.A.R.B. Loss of 'Small-World' Networks in Alzheimer's Disease: Graph Analysis of fMRI Resting-State Functional Connectivity. PLoS ONE 2010, 5, e13788. [CrossRef]

142. Wang, J.; Zuo, X.; Dai, Z.; Xia, M.; Zhao, Z.; Zhao, X.; Jia, J.; Han, Y. Disrupted Functional Brain Connectome in Individuals at Risk for Alzheimer's Disease. Biol. Psychiatry 2013, 73, 472-481. [CrossRef]

143. Zhao, X.; Liu, Y.; Wang, X.; Liu, B.; Xi, Q.; Guo, Q.; Jiang, H.; Jiang, T.; Wang, P. Disrupted Small-World Brain Networks in Moderate Alzheimer's Disease: A Resting-State fMRI Study. PLoS ONE 2012, 7, e33540. [CrossRef] [PubMed]

144. Wang, J.; Wang, X.; He, Y.; Yu, X.; Wang, H.; He, Y. Apolipoprotein E $\varepsilon 4$ modulates functional brain connectome in Alzheimer's disease. Hum. Brain Mapp. 2015, 36, 1828-1846. [CrossRef] [PubMed]

145. Quiroz, Y.T.; Schultz, A.P.; Chen, K.; Protas, H.D.; Brickhouse, M.; Fleisher, A.S.; Langbaum, J.B.; Thiyyagura, P.; Fagan, A.M.; Shah, A.R.; et al. Brain Imaging and Blood Biomarker Abnormalities in Children with Autosomal Dominant Alzheimer Disease: A Cross-Sectional Study. JAMA Neurol. 2015, 72, 912-919. [CrossRef] [PubMed] 
146. Chhatwal, J.P.; Schultz, A.P.; Johnson, K.; Benzinger, T.L.S.; Jack, C.; Ances, B.M.; Sullivan, C.A.; Salloway, S.P.; Ringman, J.M.; Koeppe, R.A.; et al. Impaired default network functional connectivity in autosomal dominant Alzheimer disease. Neurology 2013, 81, 736-744. [CrossRef] [PubMed]

147. Sala-Llonch, R.; Fortea, J.; Bartrés-Faz, D.; Bosch, B.; Lladó, A.; Peña-Gómez, C.; Antonell, A.; Castellanos-Pinedo, F.; Bargalló, N.; Molinuevo, J.L.; et al. Evolving Brain Functional Abnormalities in PSEN1 Mutation Carriers: A Resting and Visual Encoding fMRI Study. J. Alzheimer's Dis. 2013, 36, 165-175. [CrossRef] [PubMed]

148. Adriaanse, S.M.; Sanz-Arigita, E.J.; Binnewijzend, M.A.A.; Ossenkoppele, R.; Tolboom, N.; van Assema, D.M.E.; Wink, A.M.; Boellaard, R.; Yaqub, M.; Windhorst, A.D.; et al. Amyloid and its association with default network integrity in Alzheimer's disease. Hum. Brain Mapp. 2014, 35, 779-791. [CrossRef]

149. Thomas, J.B.; Brier, M.R.; Bateman, R.J.; Snyder, A.Z.; Benzinger, T.L.; Xiong, C.; Raichle, M.; Holtzman, D.M.; Sperling, R.A.; Mayeux, R.; et al. Functional Connectivity in Autosomal Dominant and Late-Onset Alzheimer Disease. JAMA Neurol. 2014, 71, 1111-1122. [CrossRef]

150. Li, X.; Westman, E.; Thordardottir, S.; Ståhlbom, A.K.; Almkvist, O.; Blennow, K.; Wahlund, L.-O.; Graff, C. The Effects of Gene Mutations on Default Mode Network in Familial \& Alzheimer's Disease. J. Alzheimer's Dis. 2017, 56, 327-334. [CrossRef]

151. Matura, S.; Prvulovic, D.; Butz, M.; Hartmann, D.; Sepanski, B.; Linnemann, K.; Oertel-Knöchel, V.; Karakaya, T.; Fußer, F.; Pantel, J.; et al. Recognition memory is associated with altered resting-state functional connectivity in people at genetic risk for Alzheimer's disease. Eur. J. Neurosci. 2014, 40, 3128-3135. [CrossRef]

152. Sheline, Y.I.; Morris, J.C.; Snyder, A.Z.; Price, J.L.; Yan, Z.; D’Angelo, G.; Liu, C.; Dixit, S.; Benzinger, T.; Fagan, A.; et al. APOE4 Allele Disrupts Resting State fMRI Connectivity in the Absence of Amyloid Plaques or Decreased CSF A 342 . J. Neurosci. 2010, 30, 17035-17040. [CrossRef]

153. Su, Y.Y.; Liang, X.; Schoepf, U.J.; Varga-Szemes, A.; West, H.C.; Qi, R.; Kong, X.; Chen, H.J.; Lu, G.M.; Zhang, L.J. APOE Polymorphism Affects Brain Default Mode Network in Healthy Young Adults: A STROBE Article. Medicine 2015, 94 , e1734. [CrossRef] [PubMed]

154. Filippini, N.; MacIntosh, B.J.; Hough, M.G.; Goodwin, G.M.; Frisoni, G.B.; Smith, S.M.; Matthews, P.M.; Beckmann, C.F.; Mackay, C.E. Distinct patterns of brain activity in young carriers of the APOE- 44 allele. Proc. Natl. Acad. Sci. USA 2009, 106, 7209-7214 [CrossRef] [PubMed]

155. Song, H.; Long, H.; Zuo, X.; Yu, C.; Liu, B.; Wang, Z.; Wang, Q.; Wang, F.; Han, Y.; Jia, J. APOE effects on default mode network in Chinese cognitive normal elderly: Relationship with clinical cognitive performance. PLoS ONE 2015, 10, 1-11. [CrossRef] [PubMed]

156. Goveas, J.S.; Xie, C.; Chen, G.; Li, W.; Ward, B.D.; Franczak, M.B.; Jones, J.L.; Antuono, P.G.; Li, S.J. Functional Network Endophenotypes Unravel the Effects of Apolipoprotein E Epsilon 4 in Middle-Aged Adults. PLoS ONE 2013, 8, 1-10. [CrossRef]

157. Westlye, E.T.; Lundervold, A.; Rootwelt, H.; Lundervold, A.J.; Westlye, L.T. Increased hippocampal default mode synchronization during rest in middle-aged and elderly APOE $\varepsilon 4$ carriers: Relationships with memory performance. J. Neurosci. 2011, 31, 7775-7783. [CrossRef]

158. Zhang, H.-Y.; Wang, S.-J.; Xing, J.; Liu, B.; Ma, Z.-L.; Yang, M.; Zhang, Z.-J.; Teng, G.-J. Detection of PCC functional connectivity characteristics in resting-state fMRI in mild Alzheimer's disease. Behav. Brain Res. 2009, 197, 103-108. [CrossRef]

159. Han, S.D.; Arfanakis, K.; Fleischman, D.A.; Leurgans, S.E.; Tuminello, E.R.; Edmonds, E.C.; Bennett, D.A. Functional connectivity variations in mild cognitive impairment: Associations with cognitive function. J. Int. Neuropsychol. Soc. 2012, 18, 39-48. [CrossRef]

160. Bai, F.; Watson, D.R.; Yu, H.; Shi, Y.; Yuan, Y.; Zhang, Z. Abnormal resting-state functional connectivity of posterior cingulate cortex in amnestic type mild cognitive impairment. Brain Res. 2009, 1302, 167-174. [CrossRef]

161. Qureshi, M.N.I.; Ryu, S.; Song, J.; Lee, K.H.; Lee, B. Evaluation of Functional Decline in Alzheimer's Dementia Using 3D Deep Learning and Group ICA for rs-fMRI Measurements. Front. Aging Neurosci. 2019, 11, 8-16. [CrossRef]

162. Goveas, J.S.; Xie, C.; Ward, B.D.; Wu, Z.; Li, W.; Franczak, M.; Jones, J.L.; Antuono, P.G.; Li, S. Recovery of Hippocampal Network Connectivity Correlates with Cognitive Improvement in Mild Alzheimer's Disease Patients Treated with Donepezil Assessed by Resting-State fMRI. J. Magn. Reson. Imaging 2011, 34, 764-773. [CrossRef]

163. Li, W.; Antuono, P.G.; Xie, C.; Chen, G.; Jones, J.L.; Ward, B.D.; Franczak, M.B.; Goveas, J.S.; Li, S. NeuroImage Changes in regional cerebral blood $\mathrm{fl}$ ow and functional connectivity in the cholinergic pathway associated with cognitive performance in subjects with mild Alzheimer's disease after 12-week donepezil treatment. Neuroimage 2012, 60, 1083-1091. [CrossRef]

164. Ferreira, L.K.; Busatto, G.F. Resting-state functional connectivity in normal brain aging. Neurosci. Biobehav. Rev. 2013, 37, 384-400. [CrossRef] [PubMed]

165. Wang, L.; Brier, M.R.; Snyder, A.Z.; Thomas, J.B.; Fagan, A.M.; Xiong, C.; Benzinger, T.L.; Holtzman, D.M.; Morris, J.C.; Ances, B.M. Cerebrospinal Fluid A 342 , Phosphorylated Tau181, and Resting-State Functional Connectivity. JAMA Neurol. 2013, 70, 1242-1248. [CrossRef] [PubMed]

166. Elman, J.A.; Madison, C.M.; Baker, S.L.; Vogel, J.W.; Marks, S.M.; Crowley, S.; O’Neil, J.P.; Jagust, W.J. Effects of Beta-Amyloid on Resting State Functional Connectivity Within and Between Networks Reflect Known Patterns of Regional Vulnerability. Cereb. Cortex 2016, 26, 695-707. [CrossRef]

167. Hafkemeijer, A.; Möller, C.; Dopper, E.G.P.; Jiskoot, L.C.; van den Berg-Huysmans, A.A.; van Swieten, J.C.; van der Flier, W.M.; Vrenken, H.; Pijnenburg, Y.A.L.; Barkhof, F.; et al. A Longitudinal Study on Resting State Functional Connectivity in Behavioral Variant Frontotemporal Dementia and Alzheimer's Disease. J. Alzheimer's Dis. 2017, 55, 521-537. [CrossRef] [PubMed] 
168. Hart, B.; Cribben, I.; Fiecas, M. A longitudinal model for functional connectivity networks using resting-state fMRI. Neuroimage 2018, 178, 687-701. [CrossRef]

169. Lau, W.K.-W.; Leung, P.P.-Y.; Chung, C.L.-P. Effects of the Satir Model on Mental Health: A Randomized Controlled Trial. Res. Soc. Work Pract. 2018, 29, 775-785. [CrossRef]

170. Zhou, J.; Greicius, M.D.; Gennatas, E.D.; Growdon, M.E.; Jang, J.Y.; Rabinovici, G.D.; Kramer, J.H.; Weiner, M.; Miller, B.L.; Seeley, W.W. Divergent network connectivity changes in behavioural variant frontotemporal dementia and Alzheimer's disease. Brain 2010, 133, 1352-1367. [CrossRef]

171. Fox, M.D.; Corbetta, M.; Snyder, A.Z.; Vincent, J.L.; Raichle, M.E. Spontaneous neuronal activity distinguishes human dorsal and ventral attention systems. Proc. Natl. Acad. Sci. USA 2006, 103, 10046-10051. [CrossRef]

172. Dosenbach, N.U.F.; Fair, D.A.; Miezin, F.M.; Cohen, A.L.; Wenger, K.K.; Dosenbach, R.A.T.; Fox, M.D.; Snyder, A.Z.; Vincent, J.L.; Raichle, M.E.; et al. Distinct brain networks for adaptive and stable task control in humans. Proc. Natl. Acad. Sci. USA 2007, 104, 11073-11078. [CrossRef]

173. Sylvester, C.M.; Shulman, G.L.; Jack, A.I.; Corbetta, M. Anticipatory and Stimulus-Evoked Blood Oxygenation Level-Dependent Modulations Related to Spatial Attention Reflect a Common Additive Signal. J. Neurosci. 2009, 29, 10671-10682. [CrossRef] [PubMed]

174. Challis, E.; Hurley, P.; Serra, L.; Bozzali, M.; Oliver, S.; Cercignani, M. Gaussian process classification of Alzheimer's disease and mild cognitive impairment from resting-state fMRI. Neuroimage 2015, 112, 232-243. [CrossRef] [PubMed]

175. Khazaee, A.; Ebrahimzadeh, A.; Babajani-Feremi, A. Identifying patients with Alzheimer's disease using resting-state fMRI and graph theory. Clin. Neurophysiol. 2015, 126, 2132-2141. [CrossRef] [PubMed]

176. Shen, K.; Welton, T.; Lyon, M.; McCorkindale, A.N.; Sutherland, G.T.; Burnham, S.; Fripp, J.; Martins, R.; Grieve, S.M. Structural core of the executive control network: A high angular resolution diffusion MRI study. Hum. Brain Mapp. 2020, 41, 1226-1236. [CrossRef]

177. Niendam, T.A.; Laird, A.R.; Ray, K.L.; Dean, Y.M.; Glahn, D.C.; Carter, C.S. Meta-analytic evidence for a superordinate cognitive control network subserving diverse executive functions. Cogn. Affect. Behav. Neurosci. 2012, 12, 241-268. [CrossRef]

178. Reineberg, A.E.; Banich, M.T. Functional connectivity at rest is sensitive to individual differences in executive function: A network analysis. Hum. Brain Mapp. 2016, 37, 2959-2975. [CrossRef]

179. Zhu, Z.; Johnson, N.F.; Kim, C.; Gold, B.T. Reduced frontal cortex efficiency is associated with lower white matter integrity in aging. Cereb. Cortex 2015, 25, 138-146. [CrossRef]

180. Rosenberg-Katz, K.; Herman, T.; Jacob, Y.; Mirelman, A.; Giladi, N.; Hendler, T.; Hausdorff, J.M. Fall risk is associated with amplified functional connectivity of the central executive network in patients with Parkinson's disease. J. Neurol. 2015, 262, 2448-2456. [CrossRef]

181. Cai, S.; Peng, Y.; Chong, T.; Zhang, Y.; von Deneen, K.M.; Huang, L. Differentiated Effective Connectivity Patterns of the Executive Control Network in Progressive MCI: A Potential Biomarker for Predicting AD. Curr. Alzheimer Res. 2017, 14. [CrossRef]

182. Zhao, Q.; Lu, H.; Metmer, H.; Li, W.X.Y.; Lu, J. Evaluating functional connectivity of executive control network and frontoparietal network in Alzheimer's disease. Brain Res. 2018, 1678, 262-272. [CrossRef]

183. Cieri, F.; Esposito, R.; Cera, N.; Pieramico, V.; Tartaro, A.; Di Giannantonio, M. Late-life depression: Modifications of brain resting state activity. J. Geriatr. Psychiatry Neurol. 2017, 30, 140-150. [CrossRef] [PubMed]

184. Respino, M.; Hoptman, M.J.; Victoria, L.W.; Alexopoulos, G.S.; Solomonov, N.; Stein, A.T.; Coluccio, M.; Morimoto, S.S.; Blau, C.J.; Abreu, L.; et al. Cognitive Control. Network Homogeneity and Executive Functions in Late-Life Depression. Biol. Psychiatry Cogn. Neurosci. Neuroimaging 2020, 5, 213-221. [CrossRef] [PubMed]

185. Manning, K.; Wang, L.; Steffens, D. Recent advances in the use of imaging in psychiatry: Functional magnetic resonance imaging of large-scale brain networks in late-life depression. F1000Research 2019, 8, 1-9. [CrossRef]

186. Alalade, E.; Denny, K.; Potter, G.; Steffens, D.; Wang, L. Altered Cerebellar-Cerebral Functional Connectivity in Geriatric Depression. PLoS ONE 2011, 6, e20035. [CrossRef] [PubMed]

187. Yin, Y.; Hou, Z.; Wang, X.; Sui, Y.; Yuan, Y. Association between altered resting-state cortico-cerebellar functional connectivity networks and mood/cognition dysfunction in late-onset depression. J. Neural Transm. 2015, 122, 887-896. [CrossRef]

188. Yue, Y.; Yuan, Y.; Hou, Z.; Jiang, W.; Bai, F.; Zhang, Z. Abnormal Functional Connectivity of Amygdala in Late- Onset Depression Was Associated with Cognitive Deficits. PLoS ONE 2013, 8, e75058. [CrossRef] [PubMed]

189. Wang, Z.; Yuan, Y.; Bai, F.; Shu, H.; You, J.; Li, L.; Zhang, Z. Altered functional connectivity networks of hippocampal subregions in remitted late-onset depression: A longitudinal resting-state study. Neurosci. Bull. 2015, 31, 13-21. [CrossRef]

190. Lockwood, K.A.; Alexopoulos, G.S.; van Gorp, W.G. Executive dysfunction in geriatric depression. Am. J. Psychiatry 2002, 159, 1119-1126. [CrossRef]

191. Manning, K.J.; Alexopoulos, G.S.; Mcgovern, A.R.; Morimoto, S.S.; Yuen, G.; Kanellopoulos, T.; Gunning, F.M. Executive functioning in late-life depression. Psychiatr. Ann. 2014, 44, 143-146. [CrossRef]

192. Gandelman, J.A.; Albert, K.; Boyd, B.D.; Park, J.W.; Riddle, M.; Woodward, N.D.; Kang, H.; Landman, B.A.; Taylor, W.D. Intrinsic Functional Network Connectivity Is Associated with Clinical Symptoms and Cognition in Late-Life Depression. Biol. Psychiatry Cogn. Neurosci. Neuroimaging 2019, 4, 160-170. [CrossRef]

193. Alexopoulos, G.S.; Kiosses, D.N.; Klimstra, S.; Kalayam, B.; Bruce, M.L. Clinical Presentation of the “Depression-Executive Dysfunction Syndrome" of Late Life. Am. J. Geriatr. Psychiatry 2002, 10, 98-106. [CrossRef] [PubMed]

194. Alexopoulos, G.S.; Kiosses, D.N.; Heo, M.; Murphy, C.F.; Shanmugham, B.; Gunning-Dixon, F. Executive Dysfunction and the Course of Geriatric Depression. Biol. Psychiatry 2005, 58, 204-210. [CrossRef] [PubMed] 
195. Manning, K.J.; Alexopoulos, G.S.; Banerjee, S.; Morimoto, S.S.; Seirup, J.K.; Klimstra, S.A.; Yuen, G.; Kanellopoulos, T.; GunningDixon, F. Executive functioning complaints and escitalopram treatment response in late-life depression. Am. J. Geriatr. Psychiatry 2015, 23, 440-445. [CrossRef] [PubMed]

196. Morimoto, S.S.; Kanellopoulos, D.; Manning, K.J.; Alexopoulos, G.S. Diagnosis and treatment of depression and cognitive impairment in late life. Ann. N. Y. Acad. Sci. 2015, 1345, 36-46. [CrossRef] [PubMed]

197. Castellazzi, G.; Palesi, F.; Casali, S.; Vitali, P.; Sinforiani, E.; Wheeler-Kingshott, C.A.M.; D’Angelo, E. A comprehensive assessment of resting state networks: Bidirectional modification of functional integrity in cerebro-cerebellar networks in dementia. Front. Neurosci. 2014, 8, 223-250. [CrossRef] [PubMed]

198. Gour, N.; Ranjeva, J.-P.; Ceccaldi, M.; Confort-Gouny, S.; Barbeau, E.; Soulier, E.; Guye, M.; Didic, M.; Felician, O. Basal functional connectivity within the anterior temporal network is associated with performance on declarative memory tasks. Neuroimage 2011, 58, 687-697. [CrossRef] [PubMed]

199. Firbank, M.; Kobeleva, X.; Cherry, G.; Killen, A.; Gallagher, P.; Burn, D.J.; Thomas, A.J.; O’Brien, J.T.; Taylor, J.P. Neural correlates of attention-executive dysfunction in lewy body dementia and Alzheimer's disease. Hum. Brain Mapp. 2016, 37, 1254-1270. [CrossRef]

200. Levine, M.E.; Lu, A.T.; Bennett, D.A.; Horvath, S. Epigenetic age of the pre-frontal cortex is associated with neuritic plaques, amyloid load, and Alzheimer's disease related cognitive functioning. Aging 2015, 7, 1198-1211. [CrossRef]

201. Liu, Y.; Yu, J.T.; Wang, H.F.; Han, P.R.; Tan, C.C.; Wang, C.; Meng, X.F.; Risacher, S.L.; Saykin, A.J.; Tan, L. APOE genotype and neuroimaging markers of Alzheimer's disease: Systematic review and meta-analysis. J. Neurol. Neurosurg. Psychiatry 2015, 86, 127-134. [CrossRef]

202. Menon, V.; Uddin, L.Q. Saliency, switching, attention and control: A network model of insula function. Brain Struct. Funct. 2010, 214, 655-667. [CrossRef]

203. Seeley, X.W.W. The Salience Network: A Neural System for Perceiving and Responding to Homeostatic Demands. J. Neurosci. 2019, 39, 9878-9882. [CrossRef] [PubMed]

204. Downar, J.; Crawley, A.P.; Mikulis, D.J.; Davis, K.D. A multimodal cortical network for the detection of changes in the sensory environment. Nat. Neurosci. 2000, 3, 277-283. [CrossRef] [PubMed]

205. Touroutoglou, A.; Hollenbeck, M.; Dickerson, B.C.; Feldman Barrett, L. Dissociable large-scale networks anchored in the right anterior insula subserve affective experience and attention. Neuroimage 2012, 60, 1947-1958. [CrossRef] [PubMed]

206. Seeley, W.W.; Menon, V.; Schatzberg, A.F.; Keller, J.; Glover, G.H.; Kenna, H.; Reiss, A.L.; Greicius, M.D. Dissociable Intrinsic Connectivity Networks for Salience Processing and Executive Control. J. Neurosci. 2007, 27, 2349-2356. [CrossRef] [PubMed]

207. Chand, G.B.; Wu, J.; Hajjar, I.; Qiu, D. Interactions of the Salience Network and Its Subsystems with the Default-Mode and the Central-Executive. Brain Connect. 2017, 7, 401-412. [CrossRef] [PubMed]

208. Elton, A.; Gao, W. Divergent task-dependent functional connectivity of executive control and salience networks. Cortex 2014, 51, 56-66. [CrossRef]

209. Bonnelle, V.; Ham, T.E.; Leech, R.; Kinnunen, K.M.; Mehta, M.A.; Greenwood, R.J.; Sharp, D.J. Salience network integrity predicts default mode network function after traumatic brain injury. Proc. Natl. Acad. Sci. USA 2012, 109, 4690-4695. [CrossRef]

210. Dai, L.; Zhou, H.; Xu, X.; Zuo, Z. Brain structural and functional changes in patients with major depressive disorder: A literature review. PeerJ 2019, 7, e8170. [CrossRef]

211. Cullen, K.R.; Westlund, M.K.; Klimes-Dougan, B.; Mueller, B.A.; Houri, A.; Eberly, L.E.; Lim, K.O. Abnormal Amygdala Resting-State Functional Connectivity in Adolescent Depression. JAMA Psychiatry 2014, 71, 1138-1147. [CrossRef]

212. Luking, K.R.; Repovs, G.; Belden, A.C.; Gaffrey, M.S.; Botteron, K.N.; Luby, J.L.; Barch, D.M. Functional Connectivity of the Amygdala in Early-Childhood-Onset Depression. J. Am. Acad. Child Adolesc. Psychiatry 2011, 50, 1027-1041.e3. [CrossRef]

213. Davey, C.G.; Whittle, S.; Harrison, B.J.; Simmons, J.G.; Byrne, M.L.; Schwartz, O.S.; Allen, N.B. Functional brain-imaging correlates of negative affectivity and the onset of first-episode depression. Psychol. Med. 2015, 45, 1001-1009. [CrossRef] [PubMed]

214. Zhang, H.; Li, L.; Wu, M.; Chen, Z.; Hu, X.; Chen, Y.; Zhu, H.; Jia, Z.; Gong, Q. Brain gray matter alterations in first episodes of depression: A meta-analysis of whole-brain studies. Neurosci. Biobehav. Rev. 2016, 60, 43-50. [CrossRef] [PubMed]

215. Wang, L.; Chou, Y.H.; Potter, G.G.; Steffens, D.C. Altered synchronizations among neural networks in geriatric depression. Biomed. Res. Int. 2015, 2015. [CrossRef]

216. Steffens, D.C.; Wang, L.; Pearlson, G.D. Functional connectivity predictors of acute depression treatment outcome. Int. Psychogeriatr. 2019, 31, 1831-1835. [CrossRef] [PubMed]

217. Fredericks, C.A.; Sturm, V.E.; Brown, J.A.; Hua, A.Y.; Bilgel, M.; Wong, D.F.; Resnick, S.M.; Seeley, W.W. Early affective changes and increased connectivity in preclinical Alzheimer's disease. Alzheimer's Dement. 2018, 10, 471-479. [CrossRef]

218. Machulda, M.M.; Jones, D.T.; Vemuri, P.; McDade, E.; Avula, R.; Przybelski, S.; Boeve, B.F.; Knopman, D.S.; Petersen, R.C.; Jack, C.R., Jr. Effect of APOE $\varepsilon 4$ status on intrinsic network connectivity in cognitively normal elderly subjects. Arch. Neurol. 2011, 68, 1131-1136. [CrossRef]

219. He, X.; Qin, W.; Liu, Y.; Zhang, X.; Duan, Y.; Song, J.; Li, K.; Jiang, T.; Yu, C. Abnormal salience network in normal aging and in amnestic mild cognitive impairment and Alzheimer's disease. Hum. Brain Mapp. 2014, 35, 3446-3464. [CrossRef]

220. Rami, L.; Sala-Llonch, R.; Solé-Padullés, C.; Fortea, J.; Olives, J.; Lladó, A.; Peña-Gómez, C.; Balasa, M.; Bosch, B.; Antonell, A.; et al. Distinct Functional Activity of the Precuneus and Posterior Cingulate Cortex During Encoding in the Preclinical Stage of Alzheimer's Disease. J. Alzheimer's Dis. 2012, 31, 517-526. [CrossRef] 
221. Scheff, S.W.; Price, D.A.; Ansari, M.A.; Roberts, K.N.; Schmitt, F.A.; Ikonomovic, M.D.; Mufson, E.J. Synaptic Change in the Posterior Cingulate Gyrus in the Progression of Alzheimer's Disease. J. Alzheimer's Dis. 2015, 43, 1073-1090. [CrossRef]

222. Mutlu, J.; Landeau, B.; Tomadesso, C.; de Flores, R.; Mézenge, F.; de La Sayette, V.; Eustache, F.; Chételat, G. Connectivity Disruption, Atrophy, and Hypometabolism within Posterior Cingulate Networks in Alzheimer's Disease. Front. Neurosci. 2016, 10, 582-591. [CrossRef]

223. Jamieson, A.; Goodwill, A.M.; Termine, M.; Campbell, S.; Szoeke, C. Depression related cerebral pathology and its relationship with cognitive functioning: A systematic review. J. Affect. Disord. 2019, 250, 410-418. [CrossRef] [PubMed]

224. Dong, X.; Yan, L.; Huang, L.; Guan, X.; Dong, C.; Tao, H.; Wang, T.; Qin, X.; Wan, Q. Repetitive transcranial magnetic stimulation for the treatment of Alzheimer's disease: A systematic review and meta-analysis of randomized controlled trials. PLoS ONE 2018, 13, 1-13. [CrossRef] [PubMed]

225. Crossley, N.A.; Mechelli, A.; Scott, J.; Carletti, F.; Fox, P.T.; McGuire, P.; Bullmore, E.T. The hubs of the human connectome are generally implicated in the anatomy of brain disorders. Brain 2014, 137, 2382-2395. [CrossRef] [PubMed]

226. Sepulcre, J.; Schultz, A.P.; Sabuncu, M.; Gomez-Isla, T.; Chhatwal, J.; Becker, A.; Sperling, R.; Johnson, K.A. In Vivo Tau, Amyloid, and Gray Matter Profiles in the Aging Brain. J. Neurosci. 2016, 36, 7364-7374. [CrossRef]

227. Curado, M.; Escolano, F.; Lozano, M.A.; Hancock, E.R. Early Detection of Alzheimer's Disease: Detecting Asymmetries with a Return Random Walk Link Predictor. Entropy 2020, 22, 465. [CrossRef]

228. Dachena, C.; Casu, S.; Fanti, A.; Lodi, M.B.; Mazzarella, G. Combined Use of MRI, fMRIand Cognitive Data for Alzheimer's Disease: Preliminary Results. Appl. Sci. 2019, 9, 3156. [CrossRef] 